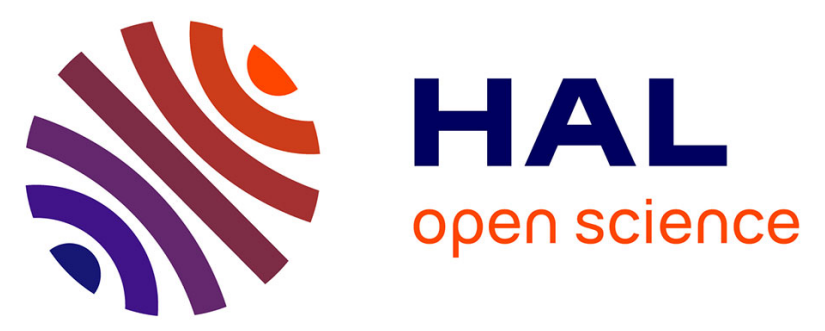

\title{
Radiocarbon Measurements of Small-Size Foraminiferal Samples with the Mini Carbon Dating System (MICADAS) at the University of Bern: Implications for Paleoclimate Reconstructions
}

\author{
Julia Gottschalk, Sönke Szidat, Elisabeth Michel, Alain Mazaud, Gary \\ Salazar, Michael Battaglia, Jörg Lippold, Samuel Jaccard
}

\section{To cite this version:}

Julia Gottschalk, Sönke Szidat, Elisabeth Michel, Alain Mazaud, Gary Salazar, et al.. Radiocarbon Measurements of Small-Size Foraminiferal Samples with the Mini Carbon Dating System (MICADAS) at the University of Bern: Implications for Paleoclimate Reconstructions. Radiocarbon, 2018, 60 (2), pp.469-491. 10.1017/RDC.2018.3 . hal-01806759

\section{HAL Id: hal-01806759 \\ https://hal.science/hal-01806759}

Submitted on 15 Jun 2021

HAL is a multi-disciplinary open access archive for the deposit and dissemination of scientific research documents, whether they are published or not. The documents may come from teaching and research institutions in France or abroad, or from public or private research centers.
L'archive ouverte pluridisciplinaire HAL, est destinée au dépôt et à la diffusion de documents scientifiques de niveau recherche, publiés ou non, émanant des établissements d'enseignement et de recherche français ou étrangers, des laboratoires publics ou privés. 


\section{RADIOCARBON MEASUREMENTS OF SMALL-SIZE FORAMINIFERAL SAMPLES WITH THE MINI CARBON DATING SYSTEM (MICADAS) AT THE UNIVERSITY OF BERN: IMPLICATIONS FOR PALEOCLIMATE RECONSTRUCTIONS}

Julia Gottschalk $^{1 *} \cdot$ Sönke Szidat $^{2} \cdot$ Elisabeth Michel $^{3}$. Alain Mazaud $^{3} \cdot$ Gary Salazar $^{2}$. Michael Battaglia $^{2}$. Jörg Lippold ${ }^{1,4}$. Samuel L Jaccard ${ }^{1}$

${ }^{1}$ Institute of Geological Sciences and Oeschger Center for Climate Change Research, University of Bern, Bern,

Switzerland.

2 Department of Chemistry and Biochemistry and Oeschger Centre for Climate Change Research, University of Bern, Bern, Switzerland.

${ }^{3}$ Laboratoire des Sciences du Climat et de l'Environnement, LSCE/IPSL, CNRS-CEA-UVSQ, Université de Paris-Saclay, Gif-sur-Yvette, France.

${ }^{4}$ Institute of Earth Sciences, Heidelberg University, Heidelberg, Germany.

ABSTRACT. Radiocarbon $\left({ }^{14} \mathrm{C}\right)$ measurements of foraminifera often provide the only absolute age constraints in marine sediments. However, they are often challenging as their reliability and accuracy can be compromised by reduced availability of adequate sample material. New analytical advances using the MIni CArbon DAting System (MICADAS) allow ${ }^{14} \mathrm{C}$ dating of very small samples, circumventing size limitations inherent to conventional ${ }^{14} \mathrm{C}$ measurements with accelerator mass spectrometry (AMS). Here we use foraminiferal samples and carbonate standard material to assess the reproducibility and precision of MICADAS ${ }^{14} \mathrm{C}$ analyses, quantify contamination biases, and determine foraminiferal ${ }^{14} \mathrm{C}$ blank levels. The reproducibility of conventional ${ }^{14} \mathrm{C}$ ages for our planktic (benthic) fora-miniferal samples from gas measurements is 200 (130) yr, and has good precision as illustrated by the agreement between both standards and their reference values as well as between small gas- and larger graphitized foraminiferal samples (within $100 \pm 60 \mathrm{yr}$ ). We observe a constant contamination bias and slightly higher ${ }^{14} \mathrm{C}$ blanks for foramini-fera than for carbonate reference materials, limiting gas (graphite) ${ }^{14} \mathrm{C}$ age determinations for foraminifera from our study sites to $\sim 38(\sim 42)$ kyr. Our findings underline the significance of MICADAS gas analyses for ${ }^{14} \mathrm{C}$ on smaller-than-conventional sized foraminiferal samples for paleoclimate reconstructions and dating.

KEYWORDS: ${ }^{14} \mathrm{C}$ backgrounds, AMS dating, foraminifera, Indian Ocean, MICADAS.

\section{INTRODUCTION}

Radiocarbon $\left({ }^{14} \mathrm{C}\right)$ analysis is a versatile method to date and characterize material from various geological archives such as speleothems, marine sediment cores, ice cores, and terrestrial sequences. Several milligrams of carbonate are required for conventional ${ }^{14} \mathrm{C}$ analysis (invol-ving sample graphitization), while the lowest limit is about 100-250 $\mu \mathrm{g} \mathrm{C}\left(\sim 0.8-2 \mathrm{mg} \mathrm{CaCO}_{3}\right)$ in most laboratories. The smaller and older the sample, the stronger may be the impact of con-tamination (for example with modern atmospheric carbon) causing higher inherent age uncertainties (Vogel et al. 1987; Brown and Southon 1997; Ruff et al. 2010a; Bard et al. 2015). For paleoclimate reconstructions, this can be an issue owing to low sample availability.

Limitations related to conventional measurements and the reduced availability of carbonaceous or carboniferous sample material in some regions and climate archives have increased the demand for ${ }^{14} \mathrm{C}$ analyses of small to ultra-small samples. This has led several laboratories world-wide to push analytical boundaries of accelerator mass spectrometry (AMS) towards smaller samples over the last decades (e.g., Pearson et al. 1998; Schleicher et al. 1998; Hua et al. 2004; Santos et al. 2007a; Ruff et al. 2010a; Smith et al. 2010; Delqué-Kolic et al. 2013; Wacker et al. 2013a; Szidat et al. 2014; Shah Walter et al. 2015; Freeman et al. 2016). Efforts to expedite small-size ${ }^{14} \mathrm{C}$ measurements with conventional graphite targets have for instance concentrated on improving the performance of the iron catalyst powder (Freeman et al. 2016), decreasing reactor volumes (Shah Walter et al. 2015), adjusting the pretreatment conditions of the iron powder (Hua et al. 2004), and/or varying the temperature during $\mathrm{CO}_{2}$ reduction (Santos et al. 2007a).

\footnotetext{
*Corresponding author. Email: julia.gottschalk@geo.unibe.ch
} 
New designs such as the MIni CArbon DAting System (MICADAS) fitted with a gas ion source allow online analysis of small-size samples in gas form, and thus the omission of sample graphitization (Synal et al. 2007; Synal 2013; Ruff et al. 2010b; Wacker et al. 2010a). The MICADAS requires smaller voltages $(200 \mathrm{kV})$ to suppress equal-mass molecules (e.g., ${ }^{13} \mathrm{C}^{1} \mathrm{H}$, ${ }^{12} \mathrm{CD},{ }^{12} \mathrm{CH}_{2},{ }^{7} \mathrm{Li}_{2}$ ) by destroying their molecular integrity in the collision/stripping unit (Suter et al. 1997; Synal et al. 2000; Schulze-König et al. 2011), and has therefore much smaller dimensions than other AMS systems (Synal et al. 2007). The MICADAS can process gaseous samples from multiple sources, i.e., from sealed glass ampoules, from the dissolution of carbonate samples in evacuated or He-filled sealed vials or from combustion of organic matter in an elemental analyzer (Ruff et al. 2010a, 2010b; Salazar et al. 2015; Wacker et al. 2013a). Improvements of the gas source such as changes to the target setup (Ruff et al. 2007; Fahrni et al. 2013) have been made to refine the carbon ion yield and the transmission efficiency within the AMS system. MICADAS ${ }^{14} \mathrm{C}$ measurements substantially reduce sample processing and measurement times owing to the omission of sample graphitization and cryogenic trapping for the purification of the sample gas, yet at the small expense of blank levels (Ruff et al. 2010a; Wacker et al. 2013b; Szidat et al. 2014). Pioneering work to improve non-graphitization analyses with MICADAS has exhibited promising outcomes, demonstrating the feasibility of analyses of samples as small as $\left.1 \mu \mathrm{g} \mathrm{C} \mathrm{(} \mathrm{8} \mu \mathrm{g} \mathrm{CaCO}_{3}\right)$ (Ruff et al. 2010a; Wacker et al. 2013a) as well as single benthic foraminifera (Wacker et al. 2013c). The lowest limit for ${ }^{14} \mathrm{C}$ analyses by MICADAS is determined by the purpose of the measurements: while ultra-small carbon masses (e.g., 1-40 $\mu \mathrm{g} \mathrm{C}$ ) can be analyzed for source apportionment (e.g., distinguishing the sources of carbon- or aerosol fractions extracted from ice cores) (Jenk et al. 2007; Ruff et al. 2010a), sample material for age determinations should ideally be larger than $\sim 40 \mu \mathrm{g} \mathrm{C}\left(\sim 300 \mu \mathrm{g} \mathrm{CaCO}_{3}\right)$ for the sake of reliability.

The MICADAS at the Laboratory for Radiocarbon Analysis with AMS at the University of Bern has been successfully applied to date wood material, plant remains, lacustrine macro-fossils, bulk sediment, charcoal (Szidat et al. 2014) and ancient bones (Szidat et al. 2017). The analyses have shown low detection limits and excellent agreement of International Atomic Energy Agency (IAEA) standards C4-C7 with their respective reference values (Szidat et al. 2014). Although foraminifera have been analyzed in other laboratories (Wacker et al. 2013a, 2013c), the reproducibility, precision and consistency of ${ }^{14} \mathrm{C}$ analyses of foraminifera with conventional AMS ${ }^{14} \mathrm{C}$ measurements remains to be comprehensively tested at the University of Bern.

Here we report the results from systematic ${ }^{14} \mathrm{C}$ analyses on planktic and benthic foraminifera (22$146 \mu \mathrm{g} \mathrm{C}, 200-1200 \mu \mathrm{g} \mathrm{CaCO} 3 ; 26-2{ }^{14} \mathrm{C}$ kyr before present, BP) and very old foraminifera devoid of ${ }^{14} \mathrm{C}$ (" ${ }^{14} \mathrm{C}$-free”) from the South Indian Ocean (sediment cores MD12-3396Q and MD11-3355) and from Ontong-Java-Plateau (sediment core RNDB-74P), performed with the MICADAS AMS at the University of Bern and with the Pelletron AMS at the University of ParisSaclay. We exclusively make use of the carbonate dissolution unit to produce sample $\mathrm{CO}_{2}$ from our marine carbonate samples, which is then directly transferred into the AMS for gas analyses, or in the case of conventional (graphite) measurements, to the graphitization unit. The goals of our study are to test and assess (1) the reproducibility and precision of gas ${ }^{14} \mathrm{C}$ mea-surements of small samples, (2) their consistency with conventional measurements of larger samples, (3) the impact of contamination during sample preparation and analysis, and (4) the ${ }^{14} \mathrm{C}$ blank levels of ${ }^{14} \mathrm{C}$-free foraminifera at our core site. We report ${ }^{14} \mathrm{C}$ values as fraction modern, $\mathrm{F}^{14} \mathrm{C}$ (Reimer et al. 2004), which is equivalent to the $A_{S N} / A_{O N}$ metric of Stuiver and Polach, (1977). 


\section{SAMPLE MATERIAL}

Sediment core MD12-3396CQ was retrieved with a kasten-square corer from a water depth of $3615 \mathrm{~m}$ from the Australian-Antarctic Basin, south of the Southeast Indian Ridge and east of Kerguelen Island $\left(47^{\circ} 43.88^{\prime} \mathrm{S} ; 8^{\circ} 41.71^{\prime} \mathrm{E}\right.$; Figure 1), as part of the Indien Sud expeditions aboard RV Marion Dufresne conducted by the French Polar Institute IPEV in 2011 and 2012. The core site is located in the Polar Frontal Zone of the Indian sector of the Southern Ocean. Bulk wet sediments were freeze-dried (at the University of Bern), were disintegrated in de-ionized water, were washed over a $150 \mu \mathrm{m}$-mesh to remove fine-grained clay particles, and were subsequently oven-dried $\left(<50^{\circ} \mathrm{C}\right)$. All foraminifera were carefully hand-picked. Sediment core MD12-3396Q extends back to $\sim 43 \mathrm{kyr}$ BP as indicated by a comparison between magnetic susceptibility records of core MD12-3396 and cores from the same region, in particular core MD94-103, which record the Laschamp geomagnetic event (not shown; Mazaud et al. 2007). ${ }^{14} \mathrm{C}$-free benthic and planktic foraminifera were therefore separated from sediment levels 3982 to $3983 \mathrm{~cm}$ of piston core MD11-3355 that was retrieved from a nearby location $\left(48^{\circ} 35.59^{\prime} \mathrm{S} ; 8^{\circ} 09.40^{\prime} \mathrm{E} ; 3976 \mathrm{~m}\right.$ water depth) and that extends to calendar ages beyond the ${ }^{14} \mathrm{C}$ application limit. According to initial core stratigraphy based on high-resolution color scan data (not shown), the selected interval corresponds to a calendar age of $\sim 160 \mathrm{kyr}$ BP (i.e., the penultimate glacial period). In addition, we have extracted ${ }^{14} \mathrm{C}$-free benthic and planktic foraminifera from sediment levels between 235-490 $\mathrm{cm}$ of piston core RNDB-74P retrieved from Ontong-Java-Plateau $\left(0^{\circ} 20.48^{\prime} \mathrm{N}, 159^{\circ} 22.49^{\prime} \mathrm{E}, 2547\right.$ $\mathrm{m}$ water depth; Figure 1). According to planktic foraminiferal $\delta^{18} \mathrm{O}$ stratigraphy, these sediment levels correspond to calendar ages older than $107 \mathrm{kyr}$ BP (Berger et al. 1996).

\section{METHODS}

\section{Experimental Setup}

\section{Reproducibility and Accuracy}

In order to assess the reproducibility and precision of gas ${ }^{14} \mathrm{C}$ measurements with the MICA-DAS at the University of Bern, we have performed multiple gas ${ }^{14} \mathrm{C}$ analyses of planktic and benthic foraminiferal samples from the deglacial section of MD12-3396Q that have a sample size between 29-138 $\mu \mathrm{g} \mathrm{C}\left(240-1150 \mu \mathrm{g} \mathrm{CaCO}_{3}\right)$. They were performed on Neogloboquadrina pachyderma $>150 \mu \mathrm{m}$ (except for one Holocene sample, where Globigerina bulloides $>200 \mu \mathrm{m}$ was used instead) and on mixed benthic foraminiferal species $>150 \mu \mathrm{m}$. The planktic

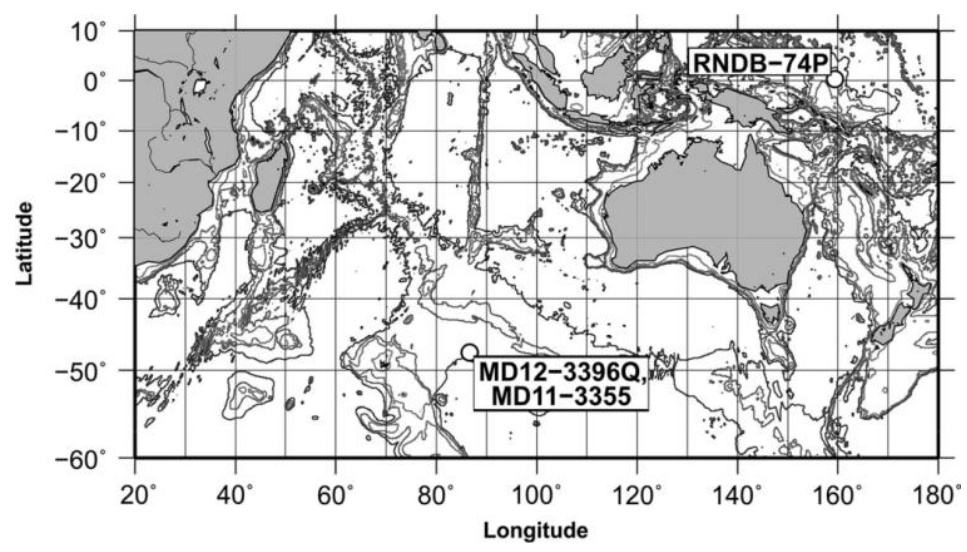

Figure 1 Location of the study cores (circles). Bathymetric isolines $(-4000 \mathrm{~m},-2000$ $\mathrm{m},-1000 \mathrm{~m}$, and $-120 \mathrm{~m}$ ) are shown as gray lines (dark to light). 
foraminiferal samples were primarily separated from or near planktic foraminiferal abundance maxima to minimize biases inherent to bioturbation. The samples are compared to graphite ${ }^{14} \mathrm{C}$ measurements performed at the University of Bern (MICADAS AMS) and the University of Paris-Saclay (Pelletron AMS).

For comparison and data correction/normalization, we have also performed multiple ${ }^{14} \mathrm{C}$ measurements of the IAEA standard C2 (travertine; consensus $\mathrm{F}^{14} \mathrm{C}$ value: $0.4114 \pm 0.0003, \delta{ }^{13} \mathrm{C}$ $=-8.25 \pm 0.31 \%$ VPDB (Rozanski 1991; Rozanski et al. 1992)) and IAEA standard C1 (marble; consensus $\mathrm{F}^{14} \mathrm{C}$ : $0.0000 \pm 0.0002$, consensus $\delta^{13} \mathrm{C}:-2.42 \pm 0.33 \%$ VPDB (Rozanski 1991; Rozanski et al. 1992)). IAEA-C2 standard sizes varied between 31-112 $\mu \mathrm{g} \mathrm{C}$ (260-930 $\mu \mathrm{g}$ $\left.\mathrm{CaCO}_{3}\right)$ for gas measurements and between 52-1000 $\mu \mathrm{g} \mathrm{C}\left(430-8330 \mu \mathrm{g} \mathrm{CaCO}_{3}\right)$ for graphite measurements, while the IAEA-C1 standard was sub-sampled with a mass varying between 8-122 $\mu \mathrm{g} \mathrm{C}\left(67-1020 \mu \mathrm{g} \mathrm{CaCO}_{3}\right)$ for gas measurements and between 38-1000 $\mu \mathrm{g} \mathrm{C} \mathrm{(320-8330} \mu \mathrm{g}$ $\mathrm{CaCO}_{3}$ ) for graphite measurements.

Samples were loaded into septum-sealed glass vials, treated with $15 \% \mathrm{H}_{2} \mathrm{O}_{2}$ for 3 min, ultrasonicated for few seconds, rinsed three times with milli-Q water $\left(25^{\circ} \mathrm{C}\right.$, TOC $\left.<5 \mathrm{ppb}\right)$, and then oven-dried at $45^{\circ} \mathrm{C}$. Cleaning aims at removing organic detritus, extraneous sediment, and det-rital carbonate attached to the foraminiferal test that could interfere with the measurements. Upon completion of the successive cleaning steps, air in the septum vials was removed and replaced by He using two concentric needles inserted through the septum by the automated carbonate handling system (CHS, Ionplus AG; Wacker et al. 2013b, 2013c). The foraminiferal samples were then weakly leached by adding $200 \mu \mathrm{HCl}(0.01 \mathrm{M})$ for $5 \mathrm{~min}$ at room temperature. After a second flush of the vials with $\mathrm{He}$ (to remove $\mathrm{CO}_{2}$ produced during leaching), $0.5 \mathrm{~mL} 85 \%$ orthophosphoric acid $\left(\mathrm{H}_{3} \mathrm{PO}_{4}\right)$ was added with a gas-tight syringe for carbonate dissolution. The reaction was run to completion over night at a temperature of $70^{\circ} \mathrm{C}$. For a gas measurement with MICADAS at the University of Bern, the sample gas is transferred to a gas interface system (GIS; Ruff et al. 2007; Wacker et al. 2013a), and subsequently into the AMS (see the section below, "MICADAS: Measurement and Instrumentation"). For graphitization at the University of Bern, the $\mathrm{CO}_{2}$ is transferred from the CHS to an automated graphitization equipment (AGE) (Wacker et al. 2010c), where it is graphitized following standard hydrogen/iron procedures (Wacker et al. 2013b). The graphite is then pressed into targets and measured with the MICADAS AMS.

At the national French ${ }^{14} \mathrm{C}$ Laboratory "ARTEMIS" at the University of Paris-Saclay, fo-raminiferal samples were treated with $2 \mathrm{~mL} 0.01 \mathrm{M} \mathrm{HNO}_{3}$ for $15 \mathrm{~min}$ in an ultrasonic bath. After vial evacuation, the sample $\mathrm{CO}_{2}$ resulting from the subsequent complete reaction of biogenic $\mathrm{CaCO}_{3}$ with orthophosphoric acid at $60^{\circ} \mathrm{C}$ was graphitized with hydrogen on iron powder at $600^{\circ} \mathrm{C}$ following established protocols (Vogel et al. 1984). The sample powder was then pressed into targets and measured with a Pelletron AMS at the University of Paris-Saclay (Moreau et al. 2013).

Thirteen of 54 IAEA-C2 standards were chemically treated (similar to the method applied for foraminifera at the University of Bern), whereas $\mathrm{H}_{2} \mathrm{O}_{2}$ treatment and the weak acid leach were omitted for the remaining 41 IAEA-C2 standards, to assess the impact of sample preparation and cleaning on the ${ }^{14} \mathrm{C}$ data. IAEA-C2 standards were analyzed both as gas- $(\mathrm{n}=31)$ and as graphite samples $(\mathrm{n}=23)$. 21 IAEA-C1 standards were chemically treated, while $\mathrm{H}_{2} \mathrm{O}_{2}$ treat-ment and weak acid leaching was omitted for the remaining 58 standards. 54 IAEA-C1 stan-dards were analyzed with the gas source, while 25 were measured as graphite.

We have additionally analyzed the National Institute of Standards and Technology (NIST) standard oxalic acid II (OxII; SRM 4990C) directly as $\mathrm{CO}_{2}$ sub-sampled from a commercially 
Small-Size Foraminiferal ${ }^{14} \mathrm{C}$ Analyses with MICADAS 5

(a)

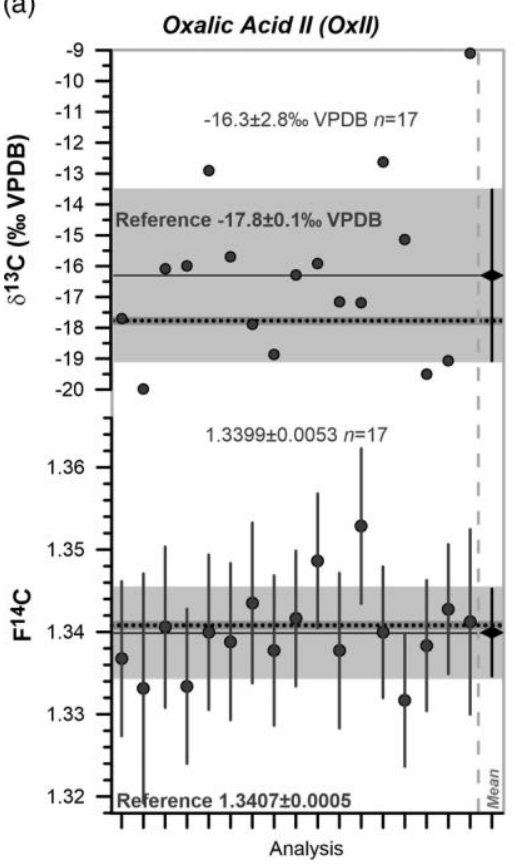

(b)

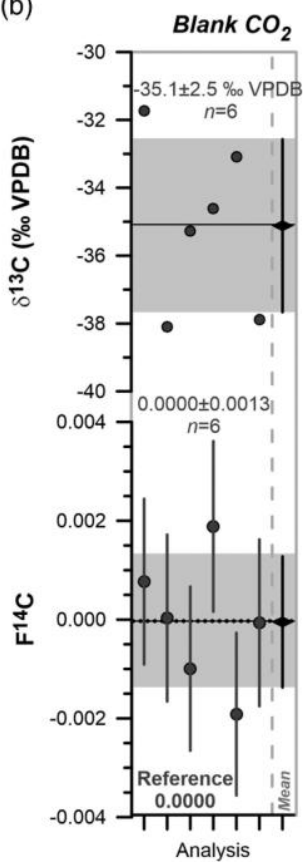

(c)

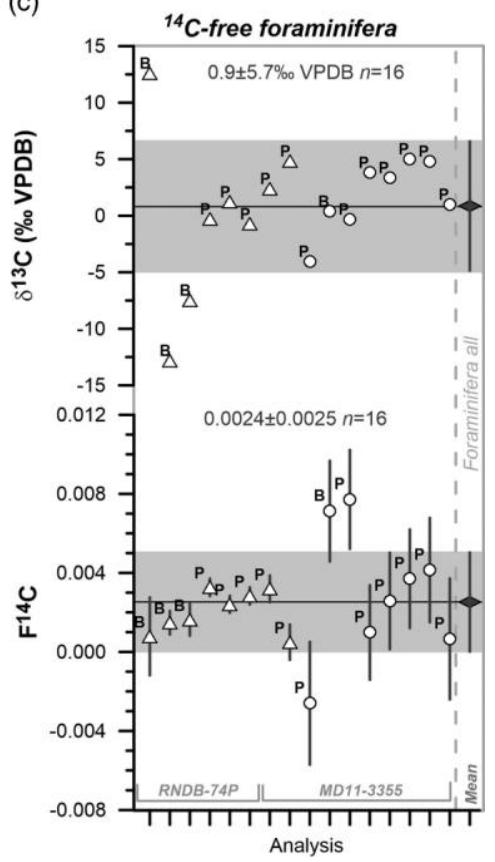

Figure $2 \delta^{13} \mathrm{C}$ (top) and $\mathrm{F}^{14} \mathrm{C}$ values (bottom) of (a) NIST standard Oxalic Acid II (OxII), (b) blank $\mathrm{CO}_{2}$, and (c) ${ }^{14} \mathrm{C}$-free planktic (P) and mixed benthic (B) foraminifera from sediment cores MD11-3355 and RNDB-74P (see also Table 1). Different symbols show different sample preparation procedures and analysis techniques: gas measurement of untreated (gray circles) and chemically treated samples (white circles) as well as graphite measurement of chemically treated samples (white triangles). Symbols and error bars to the right of the dashed line show the average and its associated onesigma uncertainty (also highlighted by black line and light gray bar). $\mathrm{F}^{14} \mathrm{C}$ values are fully corrected using IAEA-C1 and $\mathrm{C} 2$ standards for background correction and normalization, respectively. $\mathrm{F}^{14} \mathrm{C}$ values in (c) indicate foraminiferal blanks, i.e., the residual $\mathrm{F}^{14} \mathrm{C}$ value after correction and standard normalization based on IAEA-C1 and IAEA-C2 standards.

purchased gas bottle, which was obtained by combustion of large quantities of the OxII standard at the Hertelendi Laboratory of Environmental Studies, Debrecen. Sample masses were sub-sampled to amount to 100-120 $\mu \mathrm{g} \mathrm{C}$. The OxII data are not used for data correction and normalization, and can accordingly be considered as independent samples (i.e., unknowns; Figure 2).

\section{Foraminiferal Blanks}

The observed ${ }^{14} \mathrm{C}$ content of marine biogenic carbonates may be subject to an increased bias from contamination with decreasing sample size and/or increasing sample age (Ruff et al. 2010a; Bard et al. 2015; Freeman et al. 2016), and thus depend on accurate background cor-rections (Schleicher et al. 1998; Wacker et al. 2010a; Gottschalk et al. 2016). To assess ${ }^{14} \mathrm{C}$ blank levels of our samples, we have analyzed the ${ }^{14} \mathrm{C}$ content of nine ${ }^{14} \mathrm{C}$-free $\mathrm{N}$. pachyderma samples and one mixed benthic foraminiferal sample from core MD11-3355. Their size ranges between $22-146 \mu \mathrm{g}$ $\mathrm{C}\left(180-1220 \mu \mathrm{g} \mathrm{CaCO}_{3}\right)$. The analyses are complemented with analyses of three ${ }^{14} \mathrm{C}$-free planktic foraminiferal samples (Globigerinoides sacculifer) and three mixed benthic fo-raminiferal samples from RNDB-74P ranging between 52-917 $\mu \mathrm{g} \mathrm{C}\left(\sim 430-7640 \mu \mathrm{g} \mathrm{CaCO}_{3}\right)$. The foraminiferal data are compared against the IAEA standard $\mathrm{C} 1$. We have also analyzed blank $\mathrm{CO}_{2}$ samples taken directly from a commercially available sample bottle (Carbagas, Gümligen). Sizes of the blank $\mathrm{CO}_{2}$ samples were set to $100-120 \mu \mathrm{g} \mathrm{C}$. Chemical treatment was 
applied to all foraminiferal samples, independent of the analysis technique chosen. Foraminiferal samples were analyzed as gas $(n=8)$ and as graphite $(n=8)$.

\section{Graphite versus Gas Measurements}

To assess the reliability of $\mathrm{N}$. pachyderma ${ }^{14} \mathrm{C}$ ages obtained with the gas ion source, we have performed graphite ${ }^{14} \mathrm{C}$ analyses of aliquots of the same samples, both at the University of Bern ( $\mathrm{n}$ $=7$; MICADAS-200 kV) and at the University of Paris-Saclay ( $\mathrm{n}=8$; Pelletron-2.6 MV). Samples graphitized and measured at the University of Bern ranged between 76-138 $\mu \mathrm{g} \mathrm{C} \mathrm{(630-}$ $1150 \mu \mathrm{g} \mathrm{CaCO}_{3}$ ), while the samples processed at the University of Paris-Saclay were larger (220$590 \mu \mathrm{g} \mathrm{C} ; 1830-4920 \mu \mathrm{g} \mathrm{CaCO}_{3}$ ). At the University of Bern, the planktic foraminiferal sam-ples analyzed as graphite were cleaned identically to N. pachyderma samples measured with the gas ion source, while the sample cleaning at the University of Paris-Saclay was slightly different (e.g., omission of $\mathrm{H}_{2} \mathrm{O}_{2}$ cleaning step; see the previous section, "Reproducibility and Accuracy").

\section{Data Processing}

Sample batches consist of a set of standards (IAEA-C1 and IAEA-C2), analyses of OxII gas and fossil $\mathrm{CO}_{2}$ gas as well as ${ }^{14} \mathrm{C}$-free foraminiferal samples that are used for quality and consistency control and standard normalization. The data correction is performed with the help of the software BATS (version 3.6) (Wacker et al. 2010b), which includes correction for isotope fractionation (normalization to $\delta{ }^{13} \mathrm{C}=-25 \%$ VPDB). We also apply a small cross-contamination correction (memory effect) owing to $\mathrm{CO}_{2}$ adsorption within the AMS system that was shown to be $0.2 \pm$ $0.1 \%$ of the carbon mass of the previous sample for the MICADAS at the University of Bern (Salazar et al. 2015). We also correct for a measurement background that is derived from untreated IAEA-C1 and IAEA-C2 standards. It combines the background contributions resulting from the detection of apparent ${ }^{14} \mathrm{C}$ ions not originating from the carbonate of interest (e.g., through charge changes, scatter, detector anomalies, inferences, insufficient vacuum, diminished ion source quality, and detection of equal-mass molecules), the acidification of the carbonate, the transfer of the sample $\mathrm{CO}_{2}$ from the CHS through the GIS into the gas ion source, and the target production. Chemically treated IAEA-C1 and IAEA-C2 standards are used to assess the blank contribution arising from ${ }^{14} \mathrm{C}$ added during chemical cleaning from reaction vials and chemicals, i.e., the processing blank. Multiple analyses of IAEA-C1 and IAEA-C2 standards varying in size are performed to assess the impact of contamination on small samples and to quantify parameters of a constant-contamination model to correct the data (Brown and Southon 1997; Hua et al. 2004; Santos et al. 2007a, 2007b; Ruff et al. 2010b; Salazar et al. 2015). Hereafter, the combination of the corrections for cross-contamination, the measurement background and the processing blank is referred to as "correction without foraminiferal blank subtraction." Foraminiferal blanks are assessed based on multiple analyses of ${ }^{14} \mathrm{C}$-free planktic and mixed benthic foraminiferal samples of last interglacial and penultimate glacial age that are compared against the IAEA-C1 standard and our blank (fossil) $\mathrm{CO}_{2}$ analyses. Correction for foraminiferal blanks apply a simple subtraction of residual $\mathrm{F}^{14} \mathrm{C}$ values after cross-contamination-, (IAEA C1) blank- and constantcontamination correction (hereafter, referred to as "correction with foraminiferal blank subtraction"). Uncertainties of our data are fully propagated for each correction.

\section{MICADAS: Measurement and Instrumentation}

The sample $\mathrm{CO}_{2}$ is purified in the GIS by means of a X13-zeolite trap (Ruff et al. 2007; Wacker et al. 2013a). It is released by heating the trap to $500^{\circ} \mathrm{C}$, which expands the gas into a gas-tight syringe. The $\mathrm{CO}_{2}$ is mixed with $\mathrm{He}\left(\mathrm{CO}_{2} / \mathrm{He}=0.05\right)$, and is subsequently transferred into the AMS using a gas syringe with a stepping motor. Within the AMS, the $\mathrm{He}-\mathrm{CO}_{2}$ blend is fed into the Cs sputter ion 
source at a rate of $\sim 1.5 \mu \mathrm{g} \mathrm{C} \mathrm{min}{ }^{-1}$ through a gas target, where the sample $\mathrm{CO}_{2}$ is fixed on the surface of a Ti insert. The sample $\mathrm{CO}_{2}$ interacts with the $\mathrm{Cs}^{+}$beam and produces $\mathrm{C}^{-}$molecules with an efficiency of $\sim 12 \%$ (Fahrni et al. 2013). Mass separated by an initial low-energy magnet, the ion beam enters a $\mathrm{N}_{2}$-filled stripper unit within the accelerator segment, where equal-mass molecules are suppressed and where the carbon ions perform a charge state conversion (SchulzeKönig et al. 2011). A higher-energy magnet subsequently causes final mass charge-dependent separation of the ion beam, and allows detection in Faraday cups $\left({ }^{12} \mathrm{C},{ }^{13} \mathrm{C}\right)$ or in a gas ionization chamber $\left({ }^{14} \mathrm{C}\right)$. The overall transmission efficiency of carbon ions from the ion source to the detector is $\sim 40 \%$. Typical ${ }^{12} \mathrm{C}^{-}$currents during a single measurement with 120 counting cycles, each lasting $10 \mathrm{~s}$, were 10- $15 \mu \mathrm{A}$. Each measurement made use of a new Ti target surface, which was pre-sputtered for about $\sim 1$ min. During ${ }^{14} \mathrm{C}$ analyses, the zeolite trap was cleaned and prepared for a new gas sample by flushing with $\mathrm{He}$ and heating to $\sim 500^{\circ} \mathrm{C}$.

\section{RESULTS AND DISCUSSION}

\section{Accuracy and Precision}

\section{Oxalic Acid II and Blank $\mathrm{CO}_{2}$}

Analyses of 17 gas OxII standards as unknowns result in a mean $\mathrm{F}^{14} \mathrm{C}$ of $1.3399 \pm 0.0053$ using the IAEA-C2 standards for normalization, which is in agreement with the consensus value of $\mathrm{F}^{14} \mathrm{C}=1.3407 \pm 0.0005$ (Figure $2 \mathrm{a}$ ). The mean stable carbon isotope ratio of our OxII samples is $\delta^{13} \mathrm{C}=-16.3 \pm 2.8 \%$ VPDB, which is slightly higher than the reference value of $-17.8 \pm 0.1 \%$ o VPDB, but within the one-sigma uncertainty range.

Six measurements of fossil blank $\mathrm{CO}_{2}$ (Carbagas, Gümligen) show a mean $\mathrm{F}^{14} \mathrm{C}$ of $0.0000 \pm$ 0.0013 consistent with the expected value $\left(\mathrm{F}^{14} \mathrm{C}=0.0000\right.$; Figure $\left.2 \mathrm{~b}\right)$. The OxII standards and the fossil blank were provided as gaseous $\mathrm{CO}_{2}$ samples to the system, whereas the IAEA-C2 and $\mathrm{C} 1$ standards that were respectively applied for normalization and blank correction are available as carbonates, which underwent an additional step of acid treatment for transformation into $\mathrm{CO}_{2}$. The good agreement of the measurements of OxII and fossil $\mathrm{CO}_{2}$ with their reference values for both $\mathrm{F}^{14} \mathrm{C}$ and $\delta^{13} \mathrm{C}$ therefore demonstrates the excellent accuracy of the MICADAS at the University of Bern and the insignificance of fractionation contamination of the acidification step.

\section{IAEA-C2}

Our data are normalized based on the IAEA-C2 standard. The IAEA-C2 data are hence "forced" to meet their consensus $\mathrm{F}^{14} \mathrm{C}$ value, and can therefore not be independently compared against the reference value. Nonetheless, they provide useful insights into the precision of the analyses. In Figure $3 \mathrm{a}$, we show fully corrected data for IAEA-C2 standards measured as graphite and as gas.

The average $\mathrm{F}^{14} \mathrm{C}$ of chemically treated gas measurements of IAEA-C2 has the highest one-sigma uncertainty (0.0049; Table 1; Figure 3a). These analyses were made on the smallest IAEA-C2 standard aliquots in our experiments. Contamination that is unaccounted for during corrections or possible overprints inherent to chemical cleaning may have caused the large one-sigma uncertainties.

$\delta^{13} \mathrm{C}$ values of all IAEA-C2 standard sets agree with the reference value within one-sigma uncertainty, except chemically treated IAEA-C2 standards measured as gas that agree with its reference within two-sigma uncertainties (Figure $3 \mathrm{a}$ ). $\delta{ }^{13} \mathrm{C}$ values of graphite measurements of IAEA-C2 performed in 2015 (the initial phase of the MICADAS setup for carbonate 
8 J Gottschalk et al.

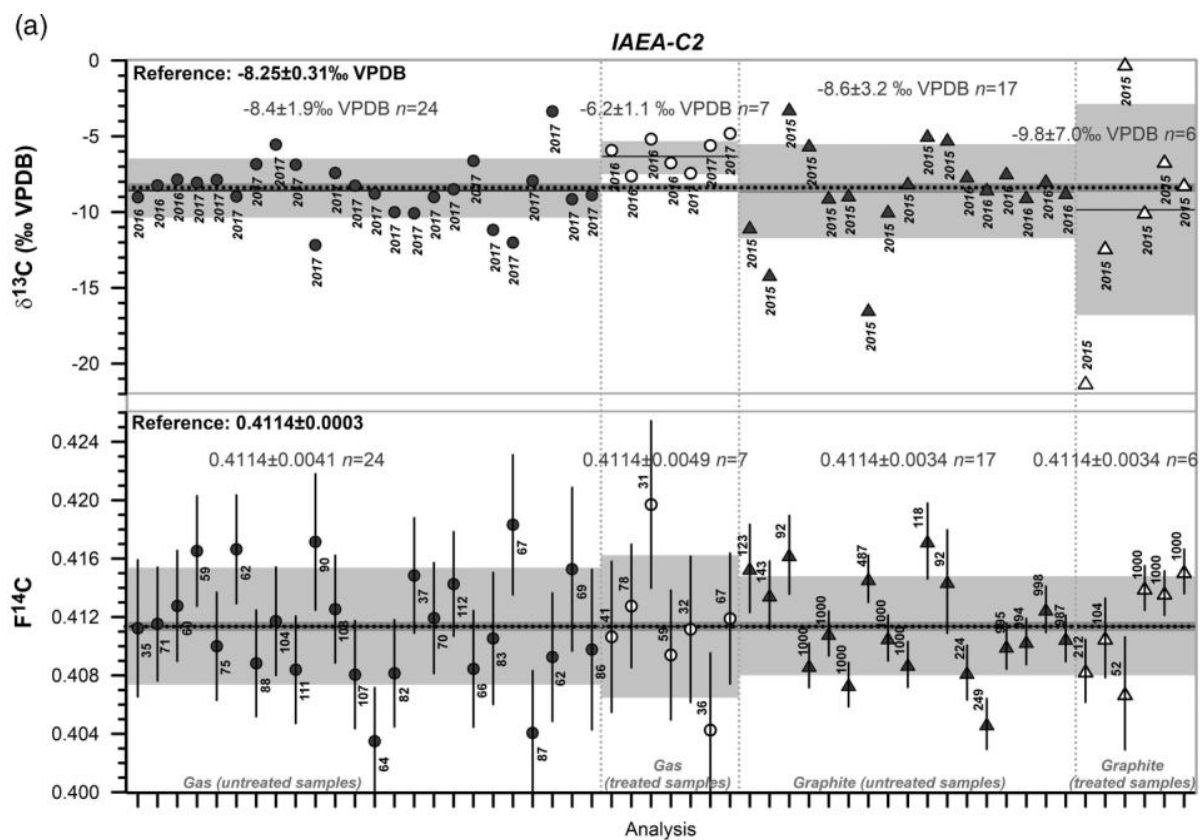

(b)

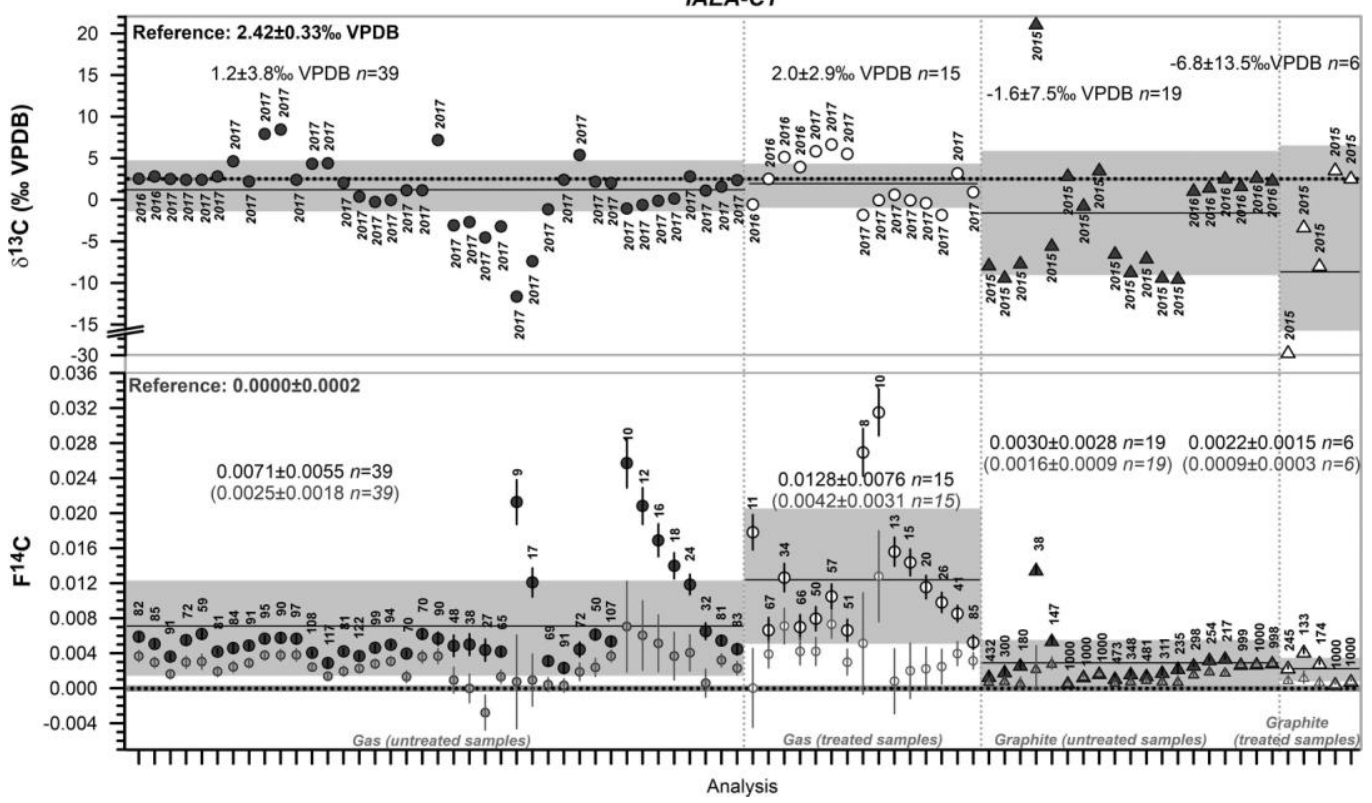

Figure $3 \delta^{13} \mathrm{C}$ - (top) and $\mathrm{F}^{14} \mathrm{C}$ values (bottom) of (a) IAEA-C2 standard and (b) IAEA-C1 standard analyses (see also Table 1). Symbols refer to sample-treatment and analysis type: gas measurements of untreated (gray circles) and chemically treated standards (white circles) as well as graphite measurements of untreated (gray triangles) and chemically treated standards (white triangles). Mean and uncertainties are highlighted as black line and light gray bar. (These uncertainties refer to the standard deviation of the mean $\mathrm{F}^{14} \mathrm{C}$ or the average of the individual uncertainties; whichever is larger.) Numbers at symbols indicate year of measurement $\left(\delta{ }^{13} \mathrm{C}\right.$ data) and size of the sample analyzed in $\mu \mathrm{g} \mathrm{C}\left(\mathrm{F}^{14} \mathrm{C}\right.$ data). IAEA-C2 standards are corrected for measurement backgrounds and are normalized to meet their consensus values. $\mathrm{F}^{14} \mathrm{C}$ values for IAEA-C1 standards are corrected for cross-contamination only (black symbols) and additionally for a constant contamination bias (gray symbols; no background subtraction). 
Table 1 Mean $\mathrm{F}^{14} \mathrm{C}$ and $\delta^{13} \mathrm{C}$ values of reference material and ${ }^{14} \mathrm{C}$-free foraminifera obtained with the MICADAS at the University of Bern. ${ }^{4} \mathrm{C}$-free foraminifera were measured as mono-specific planktic and mixed benthic samples, and were hand-picked from cores MD11-3355 (South Indian Ocean) and RNDB-74P (Ontong-Java-Plateau). Reference values are from Rozanski (1991) and Rozanski et al. (1992).

\begin{tabular}{|c|c|c|c|c|c|c|}
\hline Material/standard & Reference $\mathrm{F}^{14} \mathrm{C}$ & Measured $\mathrm{F}^{14} \mathrm{C}$ & $\begin{array}{l}\text { Average } \\
\text { sample } \\
\text { size }(\mu \mathrm{g} \mathrm{C})\end{array}$ & $\begin{array}{l}\text { Reference } \\
\delta^{13} \mathrm{C} \\
(\% \circ \text { VPDB })\end{array}$ & $\begin{array}{l}\text { Measured } \\
\delta^{13} \mathrm{C} \\
(\% \circ \mathrm{VPDB})\end{array}$ & $\begin{array}{c}\mathrm{Nr} \text { of } \\
\text { analyses (n) }\end{array}$ \\
\hline$\overline{\text { Oxalic Acid }(\mathrm{Ox}) \mathrm{II}\left(\mathrm{CO}_{2}\right)}$ & $1.3407 \pm 0.0005$ & $1.3399 \pm 0.0053^{\mathrm{a}}$ & $115 \pm 9$ & $-17.8 \pm 0.1$ & $-16.3 \pm 2.8$ & 17 \\
\hline Fossil (blank) $\mathrm{CO}_{2}$ & 0.0000 & $0.0000 \pm 0.0013^{\mathrm{a}}$ & $120 \pm 0$ & - & $-35.1 \pm 2.5$ & 6 \\
\hline IAEA-C1 (untreated, gas) & $0.0000 \pm 0.0002$ & $\begin{array}{l}0.0071 \pm 0.0055^{b} \\
0.0025 \pm 0.0018^{c}\end{array}$ & $68 \pm 32$ & $2.42 \pm 0.33$ & $1.2 \pm 3.8$ & 39 \\
\hline IAEA-C1 (treated, gas) & $0.0000 \pm 0.0002$ & $\begin{array}{l}0.0128 \pm 0.0076^{\mathrm{v}} \\
0.0042 \pm 0.0031^{\mathrm{C}}\end{array}$ & $37 \pm 25$ & $2.42 \pm 0.33$ & $2.0 \pm 2.9$ & 15 \\
\hline IAEA-C1 (untreated, graphite) & $0.0000 \pm 0.0002$ & $\begin{array}{l}0.0030 \pm 0.0028^{\circ} \\
0.0016 \pm 0.0009^{\circ}\end{array}$ & $511 \pm 357$ & $2.42 \pm 0.33$ & $-1.6 \pm 7.5$ & 19 \\
\hline IAEA-C1 (treated, graphite) & $0.0000 \pm 0.0002$ & $\begin{array}{l}0.0022 \pm 0.0015^{\mathrm{v}} \\
0.0009 \pm 0.0003^{c}\end{array}$ & $510 \pm 449$ & $2.42 \pm 0.33$ & $-6.8 \pm 13.5$ & 6 \\
\hline $\begin{array}{ll}\text { IAEA-C2 } & \text { (untreated, gas) } \\
\text { IAEA-C2 } & \text { (treated, gas) } \\
\text { IAEA-C2 } & \text { (untreated, graphite) }\end{array}$ & $\begin{array}{l}0.4114 \pm 0.0003 \\
0.4114 \pm 0.0003 \\
0.4114 \pm 0.0003\end{array}$ & $\begin{array}{l}0.4114 \pm 0.0041^{\mathrm{a}} \\
0.4114 \pm 0.0049^{\mathrm{a}} \\
0.4114 \pm 0.0034^{\mathrm{a}}\end{array}$ & $\begin{array}{c}77 \pm 21 \\
49 \pm 19 \\
618 \pm 424\end{array}$ & $\begin{array}{l}-8.25 \pm 0.31 \\
-8.25 \pm 0.31 \\
-8.25 \pm 0.31\end{array}$ & $\begin{array}{l}-8.4 \pm 1.9 \\
-6.2 \pm 1.1 \\
-8.6 \pm 3.2\end{array}$ & $\begin{array}{r}24 \\
7 \\
17\end{array}$ \\
\hline IAEA-C2 (treated, graphite) & $0.4114 \pm 0.0003$ & $0.4114 \pm 0.0034^{\mathrm{a}}$ & $561 \pm 483$ & $-8.25 \pm 0.31$ & $-9.8 \pm 7.0$ & 6 \\
\hline${ }^{14} \mathrm{C}$-free foraminifera (gas) & - & $0.0027 \pm 0.0034^{\mathrm{a}}$ & $49 \pm 19$ & - & $1.7 \pm 3.1$ & 8 \\
\hline${ }^{14} \mathrm{C}$-free foraminifera (graphite) & - & $0.0020 \pm 0.0011^{\mathrm{a}}$ & $415 \pm 378$ & - & $0.0 \pm 7.6$ & 8 \\
\hline
\end{tabular}

${ }^{\mathrm{a}}$ Value is fully corrected for the measurement background and normalized using the IAEA-C1 and C2 standards, respectively (in the case of foraminiferal samples, it does not include a foraminiferal blank subtraction).

${ }^{b}$ Value is corrected for cross-contamination, but not for the measurement background

${ }^{\mathrm{c}}$ Value is corrected for cross-contamination and a size-dependent constant contamination bias, but not for the measurement background. 
analyses) show strong deviations from the reference value, as indicated in Figure 3a, which may be associated with some fractionation processes and weaknesses of the analyses setup that were since removed.

\section{IAEA-C1}

The IAEA-C1 standard allows an assessment of the ${ }^{14} \mathrm{C}$ detection limits, and is hence crucial to determine the maximum ${ }^{14} \mathrm{C}$ age that can be reliably determined by the AMS system. Contamination substantially influences ${ }^{14} \mathrm{C}$ detection limit, and is an important control factor for the optimization of sample treatment procedures.

Aliquots of the IAEA-C1 standard were analyzed both in gaseous and solid form as well as with and without chemical treatment. We show the results of non-corrected IAEA-C1 standards that reflect the measurement background for untreated samples of various samples sizes, and in the case of chemically treated samples, may include an additional contribution from the processing blank (Figures 3 and 4).

Our untreated IAEA-C1 standards measured as gas (average standard size: $68 \pm 32 \mu \mathrm{g} \mathrm{C}$ ) show a mean background $\mathrm{F}^{14} \mathrm{C}=0.0071 \pm 0.0055(\mathrm{n}=39)$. The mean value of our chemically treated IAEA-C1 standards (average standard size: $37 \pm 25 \mu \mathrm{g} \mathrm{C})$ is slightly higher $\left(\mathrm{F}^{14} \mathrm{C}=0.0128 \pm\right.$ $0.0075 ; n=15)$, and shows higher variability, owing to the analysis of smaller standards.

The $\delta^{13} \mathrm{C}$ values of all IAEA-C1 sets are within one-sigma uncertainty of the consensus value, except treated IAEA-C1 standards measured as gas that agree within two-sigma uncertainties (Figure 3b). We reiterate that large $\delta^{13} \mathrm{C}$ deviations of IAEA-C1 standards measured in 2015, as indicated in Figure 3b, might have been linked with some (unconstrained) isotopic fractionation effects, slightly incomplete $\mathrm{CO}_{2}$ formation in the CHS and/or fractionation in the trapping system that have since been resolved.

Our mean gas ${ }^{14} \mathrm{C}$ background of untreated IAEA-C1 obtained with MICADAS at the University of Bern $\left(\mathrm{F}^{14} \mathrm{C}=0.0071 \pm 0.0055, \mathrm{n}=39\right)$ is in the same order of magnitude as those reported for other AMS systems (Ruff et al. 2007; Wacker et al. 2013c; Bard et al. 2015). Wacker et al. (2013c) reported a ${ }^{14} \mathrm{C}$ background of IAEA-C1 standard gas of $\mathrm{F}^{14} \mathrm{C}=0.0098$ $\pm 0.0010(\mathrm{n}=6)$ measured at ETH Zurich on standard sizes of $47 \pm 36 \mu \mathrm{g} \mathrm{C}$ and Bard et al. (2015) obtained $\mathrm{F}^{14} \mathrm{C}=0.0025 \pm 0.0016(\mathrm{n}=2)$ with the AixMICADAS on standard sizes of $\sim 100 \mu \mathrm{g} \mathrm{C}$. The slightly lower background levels obtained with the AixMICADAS, although measurement number is very low and standards analyzed were slightly bigger than in our experiments, may be related to a better stripping efficiency with He (Schulze-König et al. 2011), used for the AixMICADAS (Bard et al. 2015). At the University of Bern, an upgrade of the MICADAS from $\mathrm{N}_{2}$ towards the more efficient He stripper gas (Schulze-König et al. 2011) is planned for the future.

The ${ }^{14} \mathrm{C}$ background of graphite IAEA-C1 measurements is overall lower than for gas measurements, i.e., $\quad \mathrm{F}^{14} \mathrm{C}=0.0030 \pm 0.0028(\mathrm{n}=19) \quad$ for non-treated (average standard size: $511 \pm 357 \mu \mathrm{g} \quad \mathrm{C})$ and $\mathrm{F}^{14} \mathrm{C}=0.0022 \pm 0.0015 \quad(\mathrm{n}=6)$ for chemically treated standards (average standard size: $510 \pm 449 \mu \mathrm{g} \mathrm{C}$ ). This is to a large part a result of differences in sample sizes. Our results confirm previously determined graphite ${ }^{14} \mathrm{C}$ backgrounds of the MICADAS at the University of Bern $\left(\mathrm{F}^{14} \mathrm{C}=0.0018 \pm 0.0005, \mathrm{n}=7\right)$, which was based on combustion of sodium acetate (Szidat et al. 2014). They are also similar to those determined with a conventional AMS system at the University of Kiel based on IAEA-C1 

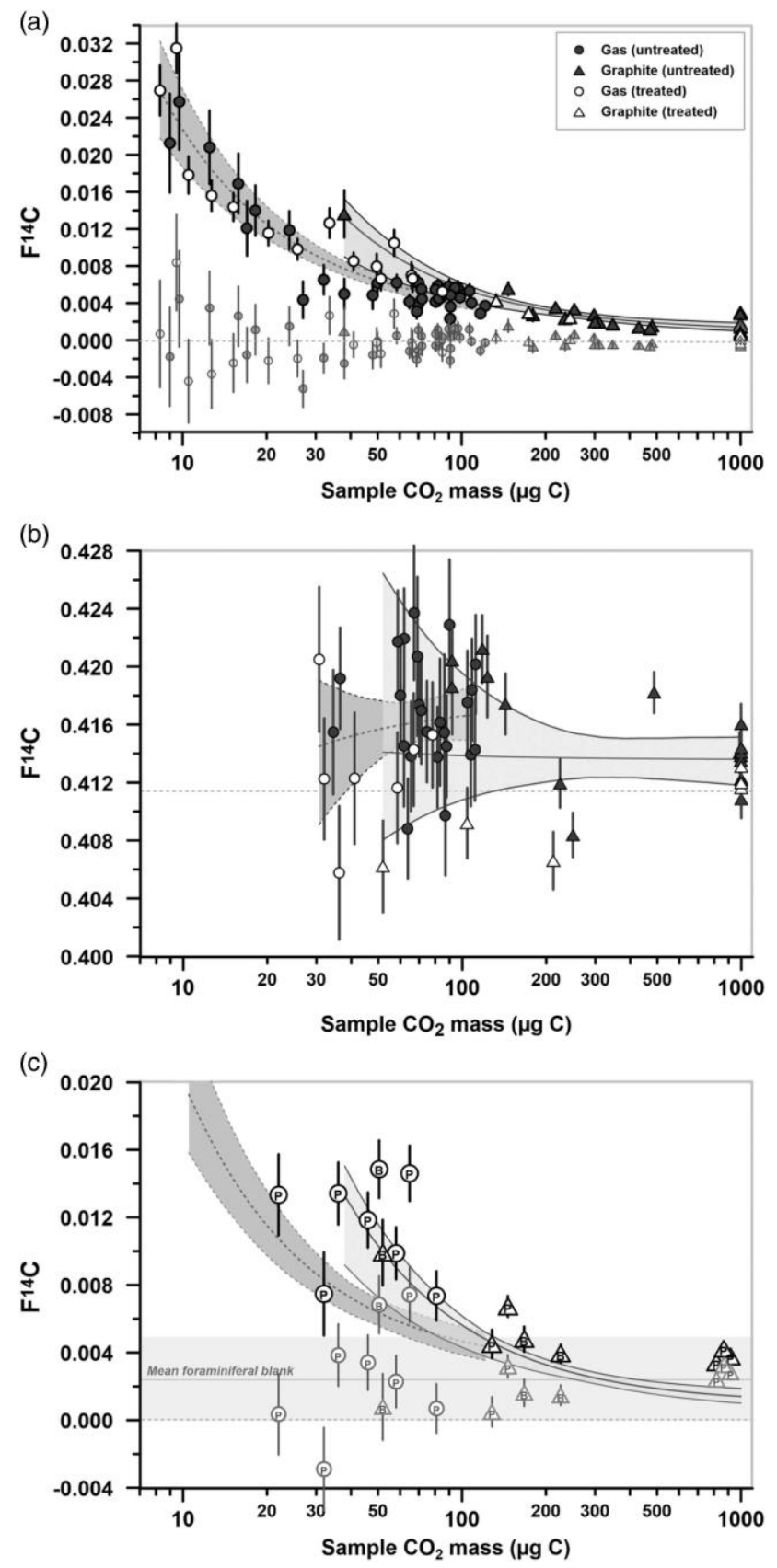

Figure $4 \mathrm{~F}^{14} \mathrm{C}$ values of (a) IAEA-C1 standard, (b) IAEA-C2 standard and (c) ${ }^{14} \mathrm{C}$-free planktic (P) and mixed benthic (B) foraminifera versus sample size (black symbols: cross-contamination correction only, gray symbols: full correction excluding foraminiferal blank subtraction). Lines and envelopes represent the applied constant contamination models for graphite samples (in light gray) and for gas samples (in dark gray); in (c) they refer to the constant contamination model obtained for IAEA-C1 standards. Dashed gray lines indicate the reference values for IAEA-C1 and IAEA-C2 (see Table 1). Horizontal line and gray box in (c) highlight the mean foraminiferal blank obtained for our study sites $\left(\mathrm{F}^{14} \mathrm{C}=0.0024\right.$ $\pm 0.0025, \mathrm{n}=16$ ). Note that the $\mathrm{x}$-axes are shown on a logarithmic scale. 
$\left(\mathrm{F}^{14} \mathrm{C}=0.0008 \pm 0.0003, \mathrm{n}=75\right.$; Nadeau et al. 2001), and to those determined with the AixMICADAS based on phthalic acid $\left(\mathrm{F}^{14} \mathrm{C}=0.0028 \pm 0.0013, \mathrm{n}=79\right.$; Bard et al. 2015).

\section{Contamination}

For gas and graphite measurements, we observe increasing IAEA-C1 $\mathrm{F}^{14} \mathrm{C}$ values of both chemically untreated and treated samples with decreasing sample size, particularly below $20 \mu \mathrm{g} \mathrm{C}$ (Figure 4). $\mathrm{F}^{14} \mathrm{C}$ values of IAEA-C2 standards remain rather constant with changing samples size (Figure 4). These trends may hint at a contamination source that has assumingly both constant mass $\left(\mathrm{m}_{\mathrm{c}}\right)$ and constant fraction modern $\left(\mathrm{F}^{14} \mathrm{C}_{\mathrm{c}}\right)$, such that $\mathrm{F}^{14} \mathrm{C}_{\mathrm{m}} \times \mathrm{m}_{\mathrm{m}}=\mathrm{F}^{14} \mathrm{C}_{\mathrm{s}} \times \mathrm{m}_{\mathrm{s}}+\mathrm{F}^{14} \mathrm{C}_{\mathrm{c}} \times$ $\mathrm{m}_{\mathrm{c}}$ (Brown and Southon 1997; Hua et al. 2004; Santos et al. 2007a, 2007b; Ruff et al. 2010b; Salazar et al. 2015), where subscripts $m$ and s refer to measurement and sample, respectively. The impact of constant contamination is reciprocally related to the sample size; its mass is assumed to be much smaller than that of the sample $\left(\mathrm{m}_{\mathrm{c}}<<\mathrm{m}_{\mathrm{S}}\right)$. Contamination influences particularly small samples, driving blank values towards higher values, as observed (Figure 4).

Graphical solution based on IAEA-C1 and C2 standards assuming constant contamination of the AMS measurement including target production (Hua et al. 2004; Ruff et al. 2010b; Salazar et al. 2015; Santos et al. 2007a) suggests an influence of $\mathrm{F}^{14} \mathrm{C}_{\mathrm{c}}=0.30 \pm 0.04(0.49 \pm 0.07)$ with $\mathrm{m}_{\mathrm{c}}=$ $0.68 \pm 0.10(0.94 \pm 0.14) \mu \mathrm{g} \mathrm{C}$ on gas (graphite) measurements with the MICADAS at the University of Bern. Uncertainties of both $\mathrm{F}^{14} \mathrm{C}_{\mathrm{c}}$ and $\mathrm{m}_{\mathrm{c}}$ are conservatively assumed to be $\pm 15 \%$ in agreement with our measurement results (see the section "Contributions to Overall ${ }^{14} \mathrm{C}$ Age Uncertainty"). Constant contamination models separately calculated for chemically treated and untreated IAEA-C1 and IAEA-C2 standards do not show any significant deviation (not shown), which indicates that contamination due to sample cleaning is potentially negligible. Our reported constant contamination model parameters for gas and graphite analyses were hence determined based on both treated and untreated standards.

Untreated IAEA-C1 standards measured as gas (average standard size: $68 \pm 13 \mu \mathrm{g}$ C) and corrected for a constant contamination bias show a mean $\mathrm{F}^{14} \mathrm{C}=0.0025 \pm 0.0018(\mathrm{n}=39)$, which suggests ${ }^{14} \mathrm{C}$ detection limits of $43.8 \mathrm{kyr}$ and better (Figure 3). The mean blank value of our chemically treated IAEA-C1 standards (average standard size: $37 \pm 25 \mu \mathrm{g} \mathrm{C}$ ) similarly corrected for a constant contamination bias is $\mathrm{F}^{14} \mathrm{C}=0.0042 \pm 0.0031(\mathrm{n}=15)$ (Figure 3), and implies overall slightly lower ${ }^{14} \mathrm{C}$ detection limits of $39.5 \mathrm{kyr}$ and better. We find that chemical treatment (i.e., $\mathrm{H}_{2} \mathrm{O}_{2}$ treatment) of the samples does not have a significant positive effect on blank values, and may therefore be omitted.

Applying a correction according to the constant contamination model and performing a data normalization, the ${ }^{14} \mathrm{C}$ background of graphite IAEA-C1 measurements is $\mathrm{F}^{14} \mathrm{C}=0.0016 \pm$ $0.0009(\mathrm{n}=19)$ for non-treated and $\mathrm{F}^{14} \mathrm{C}=0.0009 \pm 0.0003(\mathrm{n}=6)$ for chemically treated standards, which implies ${ }^{14} \mathrm{C}$ detection limits of $48.1 \mathrm{kyr}$ and better (Figure 3). Our analyses show the capability and accuracy of the Bern MICADAS to measure small samples up to $\sim 50 \mathrm{kyr}$ in solid form (graphite) and up to $\sim 45 \mathrm{kyr}$ in gaseous form; the first value is similar to conventional AMS systems.

Nonetheless, the determination of the constant contamination model is associated with rela-tively high uncertainties. Given its influence on corrected ${ }^{14} \mathrm{C}$ ages and ${ }^{14} \mathrm{C}$ detection limits, it is crucial to determine the impact of contamination on small samples (i.e., $\mathrm{m}_{\mathrm{c}}$ and $\mathrm{F}^{14} \mathrm{C}_{\mathrm{c}}$ ) accurately. We suggest that MICADAS gas measurements should ideally include a modern carbonate standard that can be measured with the MICADAS gas interface, and that can 
experience the same chemistry as the actual samples (from preparation to sample $\mathrm{CO}_{2}$ production). Such certified reference material is currently not available.

\section{Foraminiferal Blanks}

Given different surface morphologies and mineral structures, foraminiferal carbonate and IAEA standard material may yield different ${ }^{14} \mathrm{C}$ blank values. Ramped leaching experiments have emphasized the necessity of carefully removing any carbonaceous external phase that may bias the measurements (Schleicher et al. 1998; Bard et al. 2015). The residual $\mathrm{F}^{14} \mathrm{C}$ value of ${ }^{14} \mathrm{C}$-free foraminiferal samples from our study sites after correction is $\mathrm{F}^{14} \mathrm{C}=0.0027 \pm 0.0034(\mathrm{n}=8)$, when foraminifera were measured as gas (average sample size: $49 \pm 19 \mu \mathrm{g} \mathrm{C}$ ), and $\mathrm{F}^{14} \mathrm{C}=0.0020$ $\pm 0.0011(\mathrm{n}=8)$, when they were measured as graphite (average sample size: $415 \pm 378 \mu \mathrm{g} \mathrm{C}$ ). Our estimated foraminiferal blanks are consistent with foraminiferal ${ }^{14} \mathrm{C}$ blanks obtained with other AMS systems that range between $\mathrm{F}^{14} \mathrm{C}=0.0010$ and 0.0058 (Schleicher et al. 1998; Nadeau et al. 2001; Wacker et al. 2013c). For our study sites, these foraminiferal blanks translate into maximum conventional ${ }^{14} \mathrm{C}$ ages of foraminiferal samples of $38.0 \mathrm{kyr}$ (gas) and $42.4 \mathrm{kyr}$ (graphite) that can be determined with the MICADAS at the University of Bern.

The analyses emphasize the importance of correcting foraminiferal ${ }^{14} \mathrm{C}$ ages based on foraminiferal blanks, particularly for old and small samples. A foraminiferal blank likely results from ${ }^{14} \mathrm{C}$ addition during early diagenesis in marine sediments (e.g., in carbonate coatings) or during core storage, and/or through $\mathrm{CO}_{2}$ adsorption during AMS analysis. Although ${ }^{14} \mathrm{C}$-free foraminifera from the sediment core are often used to correct for the presence of contaminant ${ }^{14} \mathrm{C}$, it remains to be tested whether they faithfully reflect the ${ }^{14} \mathrm{C}$ bias of non- ${ }^{14} \mathrm{C}$-free foraminifera from shallower core depths. Hence, foraminiferal blank corrections are associated with substantial uncertainties, and a universal foraminiferal blank for a specific region, or even for a single sediment core, does not likely exist. Nonetheless, assuming that ${ }^{14} \mathrm{C}$ is preferentially added to foraminifera rather than removed during post-mortem burial in sediments and during analysis, foraminiferal blank corrections may alleviate an overestimation of true ${ }^{14} \mathrm{C}$ ages.

\section{Reproducibility}

\section{Multiple $\mathrm{CO}_{2}$ Gas Measurements}

We have performed 13 replicate measurements on N. pachyderma $(n=8)$, G. bulloides $(n=1)$ and mixed benthic foraminifera $(n=4)$ either in the same or different sample batches in order to test the reproducibility of single gas measurements. Our samples were run as duplicates $(n=10)$, triplicates $(n=1)$ and quadruplicates $(n=2)$. We show the results with and without fo-raminiferal blank subtraction (Figure 5), which are taken as monthly- rather than long-term means and can therefore differ among analyses. While reporting results for both datasets, we mainly focus on discussing ${ }^{14} \mathrm{C}$ results excluding a foraminiferal blank subtraction because they are more comparable with conventional (graphite) ${ }^{14} \mathrm{C}$ data of cores (including MD12-3396Q) for which foraminiferal blank estimates are not sufficiently constrained or absent.

Most of the ${ }^{14} \mathrm{C}$ age replicates measured either in the same batch or in different sample batches agree within their one-sigma uncertainties (Figure 5). Exceptions are observed for five (three) samples without (with) foraminiferal blank subtraction (out of 13), primarily for the planktic foraminiferal samples, that nonetheless agree within reported two-sigma uncertainties. On average, planktic foraminiferal ${ }^{14} \mathrm{C}$ ages can be reproduced within 200 (200) yr without (with) foraminiferal blank subtraction, while the reproducibility for benthic foraminiferal ${ }^{14} \mathrm{C}$ dates is 
$14 \mathrm{~J}$ Gottschalk et al.
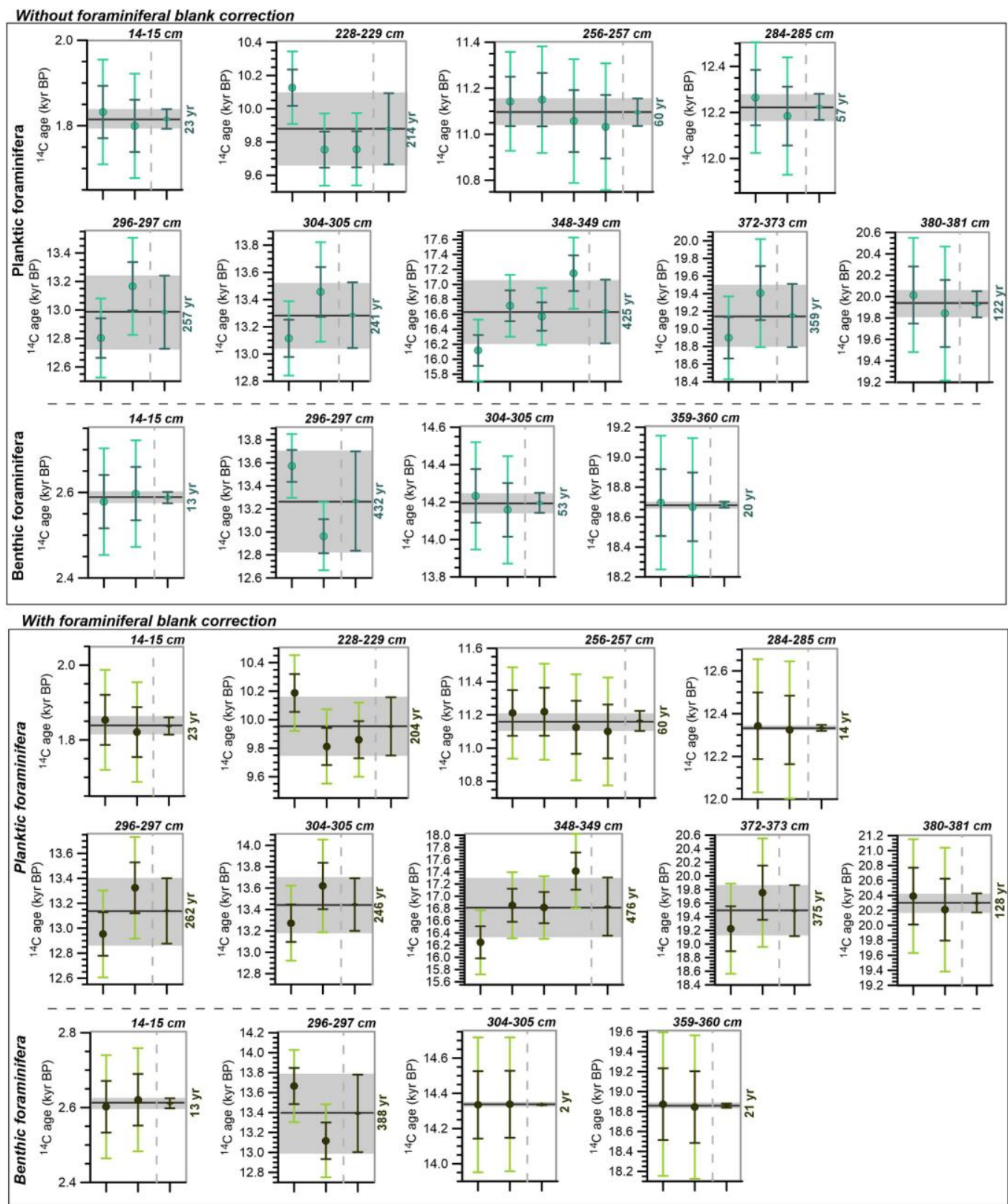

Figure 5 Replicate ${ }^{14} \mathrm{C}$ analyses of planktic and mixed benthic foraminifera from sediment core MD12-3396Q. Sediment depths of the samples are given in the upper right corner of each graph. Top and bottom panel shows corrected ${ }^{14} \mathrm{C}$ data (including cross-contamination, constant contamination, measurement background and standard normalization) without and with foraminiferal blank subtraction, respectively. N. pachyderma was used for all samples except for sample 14-15 $\mathrm{cm}$, where G. bulloides was chosen instead. Dark and light error bars indicate one-and two-sigma uncertainties of the ${ }^{14} \mathrm{C}$ ages, respectively. Symbols and error bars to the right of the dashed line show means and the associated one-sigma standard deviation (highlighted by black line and gray band throughout each graph). Tick label interval is $0.2 \mathrm{kyr}$. See online version for colors. 
better by a factor of $\sim$ two, i.e., 130 (100) yr. These estimates are similar to the average one-sigma uncertainty of the individual analyses, which is $160 \pm 70(210 \pm 100)$ yr without (with) foraminiferal blank subtraction.

The average reproducibility of multiple ${ }^{14} \mathrm{C}$ analyses of one and the same sample lies within $1.4 \pm$ $0.6 \%$ and is a confirmation of the quality of ${ }^{14} \mathrm{C}$ analyses at the University of Bern. The reproducibility of benthic foraminiferal ${ }^{14} \mathrm{C}$ dates is better than that of planktic foraminifera, which may reflect more stable hydrographic conditions in the deep ocean than at the surface. However, the difference in ${ }^{14} \mathrm{C}$ age reproducibility also raises questions on analytical limitations versus contributions from true sedimentary biases. On the one hand, planktic foraminifera may be more prone to contamination owing to their more porous and more fragile tests, which renders partial dissolution, recrystallization, adsorption of modern $\mathrm{CO}_{2}$ and/or precipitation of authigenic phases both during sample preparation and analysis as well as in the sediment more likely (Broecker et al. 2006). On the other hand, as the average sample size of our gas mea-surements on planktic foraminiferal samples is $60 \pm 20 \mu \mathrm{g} \mathrm{C}\left(500 \pm 170 \mu \mathrm{g} \mathrm{CaCO}_{3}\right)$, representing roughly 80120 individuals of $\mathrm{N}$. pachyderma, deviations of small-size sample replicates may represent true deviations from the sample mean. The lower limit of sample sizes for ${ }^{14} \mathrm{C}$ gas analyses of planktic foraminifera with the MICADAS is hence determined by the extent to which small samples are representative of their sample mean, which depends on environmental conditions (e.g., reservoir age variability, hydrographic variations, foraminiferal habitat shifts) and post-depositional processes (e.g., local accumulation rates, bioturbation, sediment redis-tribution processes, the core quality, and the extent of early diagenetic overprints such as carbonate dissolution). These factors may substantially differ from site to site, which may lead to a varying degree of ${ }^{14} \mathrm{C}$ age reproducibility and precision of MICADAS ${ }^{14} \mathrm{C}$ gas analyses of samples from different marine sediment cores. Although this requires systematic analyses on multiple planktic foraminiferal species in the future, the findings indicate that the reproduci-bility of gas ${ }^{14} \mathrm{C}$ analyses of planktic foraminifera may be compromised by increasing biases from natural sample variability towards very low sample sizes (e.g., $<200-300 \mu \mathrm{g} \mathrm{CaCO}_{3}$ ).

\section{Comparison of Graphite and Gas ${ }^{14} \mathrm{C}$ Measurements}

To compare the consistency between gas and graphite ${ }^{14} \mathrm{C}$ analyses, we have performed multiple

${ }^{14} \mathrm{C}$ analyses of aliquots of the same planktic foraminiferal sample in gaseous and solid form. In Figure 6, we compare (1) gas and graphite ${ }^{14} \mathrm{C}$ measurements at the University of Bern (MICADAS, $\mathrm{n}=7$ ), (2) gas measurements at the University of Bern (MICADAS) with graphite analyses at the University of Paris-Saclay $(n=8)$, and (3) graphite measurements at the University of Bern and Paris-Saclay $(\mathrm{n}=2)$.

The sample sizes of gas $\left(50 \pm 10 \mu \mathrm{g} \mathrm{C} ; 420 \pm 80 \mu \mathrm{g} \mathrm{CaCO}_{3}\right)$ and graphite measurements $(100 \pm$ $\left.20 \mu \mathrm{g} \mathrm{C} ; 830 \pm 170 \mu \mathrm{g} \mathrm{CaCO}_{3}\right)$ at the University of Bern differ by a factor of two. Aver-aging replicate gas measurements, gas and graphite ${ }^{14} \mathrm{C}$ ages agree within two (one) standard deviations in six (five) out of seven cases. The mean standard deviation between gas and graphite measurements at the University of Bern is $170 \pm 140 \mathrm{yr}(\mathrm{n}=7)$, which is similar to the mean onesigma ${ }^{14} \mathrm{C}$ age uncertainty of the graphite measurements and gas replicates $(140 \pm 70 \mathrm{yr}, \mathrm{n}=14)$.

Graphite measurements at the University of Paris-Saclay were performed on much larger sample aliquots $\left(380 \pm 130 \mu \mathrm{g} \mathrm{C} ; 3170 \pm 1080 \mu \mathrm{g} \mathrm{CaCO}_{3}\right)$ than gas measurements at the Uni-versity of Bern $(50 \pm 10 \mu \mathrm{g} \mathrm{C} ; 420 \pm 80 \mu \mathrm{g} \mathrm{CaCO}$ ). Both are consistent within one-sigma stan-dard deviation in most cases (Figure 6). In one case (i.e., $404-405 \mathrm{~cm}$ ), the ${ }^{14} \mathrm{C}$ results for the gas 
$16 \mathrm{~J}$ Gottschalk et al.
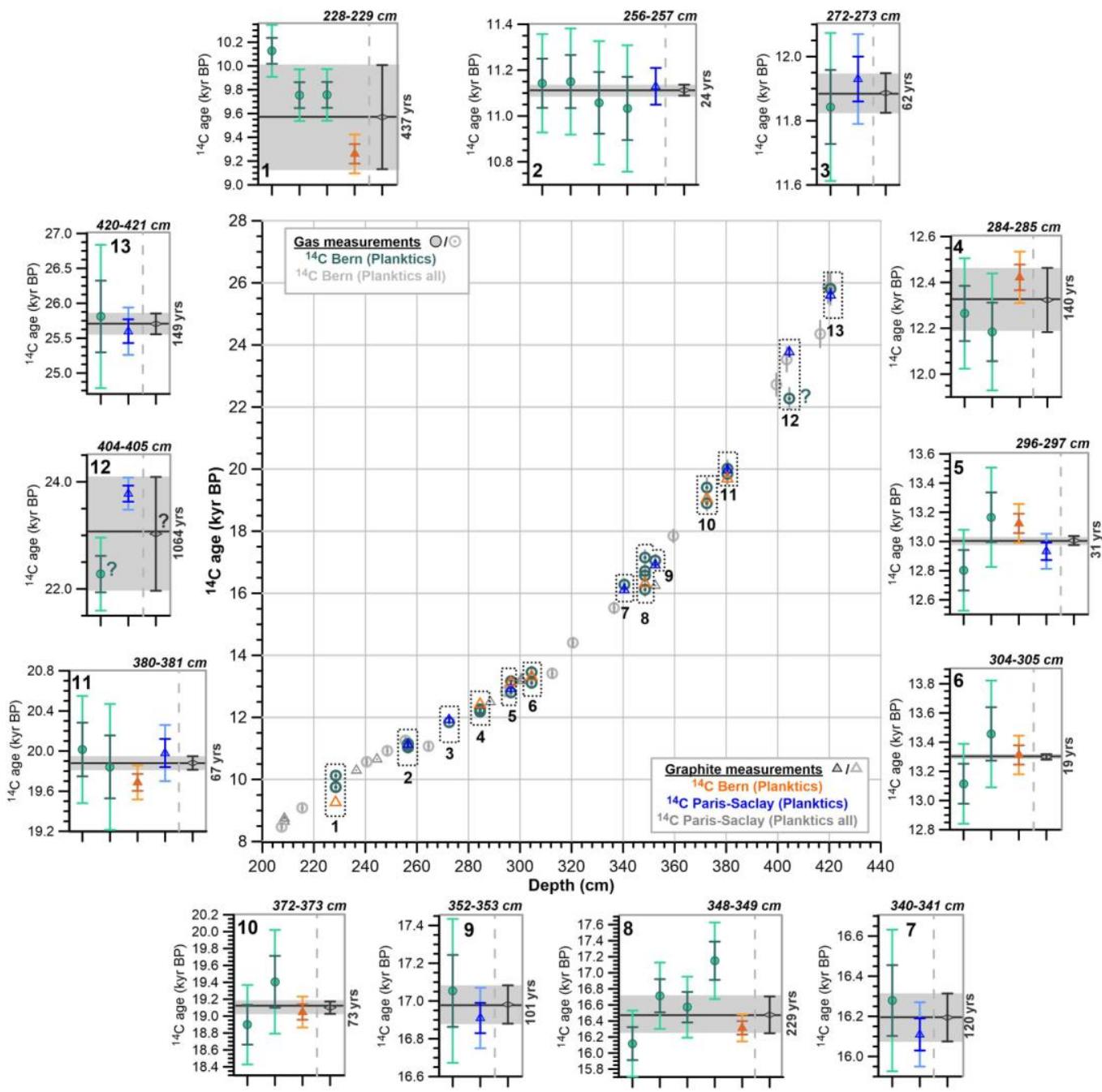

Figure $6{ }^{14} \mathrm{C}$ age-depth relationship of sediment core MD12-3396Q (center graph) based on gas ${ }^{14} \mathrm{C}$ measurements (circles) and graphite ${ }^{14} \mathrm{C}$ measurements (triangles) of the planktic foraminiferal species N. pachyderma obtained at the University of Bern (MICADAS AMS) and the University of Paris-Saclay (ARTEMIS Pelletron AMS). ${ }^{14} \mathrm{C}$ ages are fully corrected (measurement background, constant contamination, standard normalization and cross-contamination), but do not include a foraminiferal blank subtraction (to warrant a reliable comparison between gas and graphite measurements). Gray symbols refer to additional non-replicated ${ }^{14} \mathrm{C}$ analyses of $\mathrm{N}$. pachyderma obtained at the University of Bern and of other mono-specific planktic foraminiferal samples measured at the University of Paris-Saclay. Numbers and insets refer to graphs surrounding the center figure showing a detailed comparison of gas and graphite ${ }^{14} \mathrm{C}$ ages. Symbols and labels to the right of the dashed lines show means and one-sigma standard deviations of gas ${ }^{14} \mathrm{C}$ ages and graphite ${ }^{14} \mathrm{C}$ ages. (Please note that samples graphitized and analyzed in Paris-Saclay at 380-381 cm [No. 11] and 420-421 cm [No. 13] were assumingly mixed during analysis. We show them in the expected order.) See online version for colors.

sample significantly deviates from that of the graphite ${ }^{14} \mathrm{C}$ measurements performed in ParisSaclay, and the overall ${ }^{14} \mathrm{C}$ age-depth relationship in MD12-3396Q (Figure 6). Macroscopic sediment disturbances such as strong bioturbation or sediment remobilization could not be observed in the core, which makes it difficult to explain such strong deviation. The cause of this deviation remains unknown. However, taking this single outlier aside, the mean standard 
deviation between gas ${ }^{14} \mathrm{C}$ analyses of small samples at the University of Bern and graphite ${ }^{14} \mathrm{C}$ analyses of large samples at the University of Paris-Saclay is $100 \pm 60 \mathrm{yr}(\mathrm{n}=7)$, which is remarkably low given a sample mass difference by a factor of eight.

We also compare two graphite measurements obtained at the University of Bern and the University of Paris-Saclay (Figure 6). Both agree within two-sigma uncertainties, whereby one agrees within one-sigma uncertainties. However, more analyses are required to assess the consistency between MICADAS AMS ${ }^{14} \mathrm{C}$ analyses on small graphitized samples $(\sim<100 \mu \mathrm{g} \mathrm{C})$ and conventional AMS ${ }^{14} \mathrm{C}$ analyses on large graphitized samples $(>100 \mu \mathrm{g} \mathrm{C})$.

The agreement of graphite ${ }^{14} \mathrm{C}$ ages of large samples (Paris-Saclay) and gas ${ }^{14} \mathrm{C}$ measurements on small samples (Bern) supports the accuracy and precision of ${ }^{14} \mathrm{C}$ measurements on gas samples with the MICADAS at the University of Bern. In the absence of foraminiferal standards, we consider the foraminiferal graphite ${ }^{14} \mathrm{C}$ analyses a benchmark for ${ }^{14} \mathrm{C}$ gas analyses. However, biases of graphite ${ }^{14} \mathrm{C}$ ages such as due to variations in depth habitats of foraminifera (Andrée et al. 1986), short-term hydrographic changes (Magana et al. 2010; Roach et al. 2013; Lindsay et al. 2015; Ezat et al. 2017), post-depositional addition of secondary calcite (Broecker et al. 2006; Wycech et al. 2016) or sedimentary mixing (Andrée et al. 1986; Barker et al. 2007) may lead to deviations in ${ }^{14} \mathrm{C}$ ages of graphitized samples beyond the analytical uncertainty. These biases may therefore restrict the use of graphite ${ }^{14} \mathrm{C}$ ages as benchmark for comparison with gas ${ }^{14} \mathrm{C}$ measurements to some extent. Despite this cautionary note, our findings indicate that although single graphite ${ }^{14} \mathrm{C}$ ages are more precise than a single gas ${ }^{14} \mathrm{C}$ age, high-resolution gas ${ }^{14} \mathrm{C}$ age analyses can compensate for their lower precision, and provide reliable information for age chronologies.

The standard deviation of mean gas ${ }^{14} \mathrm{C}$ ages of small samples and mean graphite ${ }^{14} \mathrm{C}$ ages obtained both at the University of Bern and the University of Paris-Saclay is $120 \pm 120 \mathrm{yr}(\mathrm{n}=12$; Figure 6), which is similar to the average uncertainty of the graphite measurements $(90 \pm 30 \mathrm{yr}, \mathrm{n}$ =16). We conclude that gas ${ }^{14} \mathrm{C}$ analyses of small foraminiferal samples with MICADAS are sufficiently accurate for ${ }^{\mathrm{P}} \mathrm{C}$ dating of foraminifera in mass-limited samples and regions, if important criteria with respect to sedimentation rates $\left(>5 \mathrm{~cm} \mathrm{kyr}^{-1}\right)$, integrity of the sediment core (undisturbed) and bioturbation (low) are fulfilled. Despite the sufficient accuracy, the precision of ${ }^{14} \mathrm{C}$ gas analyses of foraminifera is slightly lower than for conventional AMS systems, as was previously shown for other environmental materials at the University of Bern (Szidat et al. 2017, 2014).

\section{Uncertainties}

\section{Comparison of Graphite and Gas ${ }^{14} \mathrm{C}$ Age Uncertainties}

Significantly larger uncertainties of ${ }^{14} \mathrm{C}$ ages are observed for gas than for graphite measure-ments (Figure 7). For gas (graphite), these uncertainties are below $110(50) \mathrm{yr}$ for ${ }^{14} \mathrm{C}$ ages younger than $12 \mathrm{kyr} \mathrm{BP}$, and between 110 (50) and 550 (190) yr for ${ }^{14} \mathrm{C}$ ages between 12 and $26 \mathrm{kyr} \mathrm{BP}$ (Figure $7)$. The average difference therefore ranges from a factor of $\sim$ two during the Holocene to a factor of $\sim$ three during the last ice age. Our dataset indicates that age uncer-tainties of graphite samples larger than $\sim 250 \mu \mathrm{g} \mathrm{C}\left(\sim 2000 \mu \mathrm{g} \mathrm{CaCO}_{3}\right)$ and of gas samples larger than $\sim 40 \mu \mathrm{g} \mathrm{C}(\sim 300 \mu \mathrm{g}$ $\mathrm{CaCO}_{3}$ ) rapidly increase with ${ }^{14} \mathrm{C}$ age (Figure 8). This increase appears independent of the samples size. However, below $\left.\sim 250 \mu \mathrm{g} \mathrm{C}(\sim 2000 \mu \mathrm{g} \mathrm{CaCO})_{3}\right)$ and $\sim 40 \mu \mathrm{g} \mathrm{C}\left(\sim 330 \mu \mathrm{g} \mathrm{CaCO}_{3}\right)$, age uncertainties increase both as a function of increasing ${ }^{14} \mathrm{C}$ age and decreasing sample size (Figure 8). More measurements are required to describe these dependencies more precisely. Although graphite samples analyzed at the University of Bern were overall much smaller $(100 \pm$ $20 \mu \mathrm{g} \mathrm{C} ; \mathrm{n}=7$ ) than those measured at the University of 


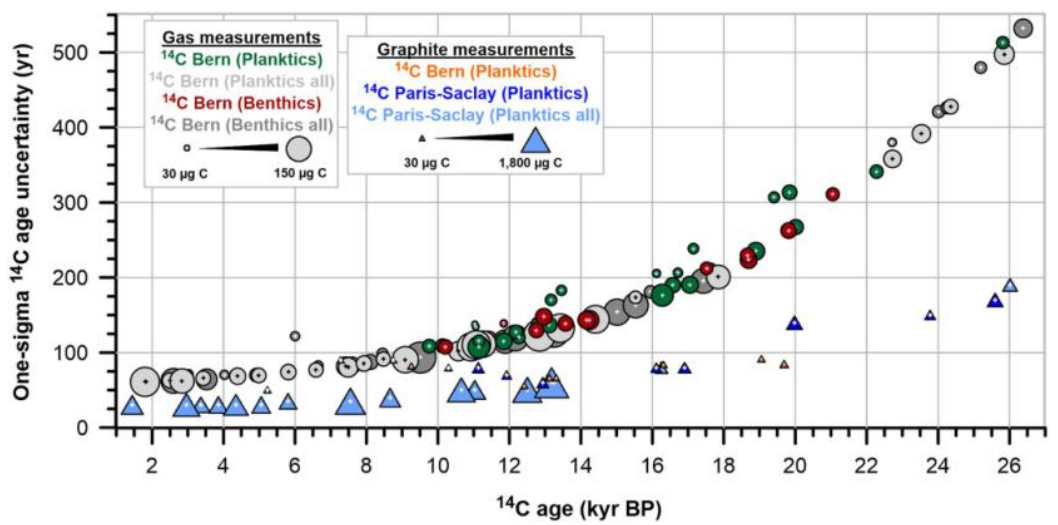

Figure 7 One-sigma ${ }^{14} \mathrm{C}$ age uncertainties of planktic and mixed benthic foraminifera (foraminiferal blank not subtracted) from sediment core MD12-3396Q measured as gas (circle) and as graphite (triangle) at the University of Bern (MICADAS AMS) and the University of Paris-Saclay (ARTEMIS Pelletron AMS). Symbol size varies with sample size as shown in the legend. Colored symbols refer to the data shown in Figures 5 and 6; for completeness, pale symbols show all data obtained in both laboratories (including those without replicate analyses). Note that ${ }^{14} \mathrm{C}$ age uncertainties are to some extent dependent on protocols of normalization and data correction that may differ among laboratories (see the section "Contributions to Overall ${ }^{14} \mathrm{C}$ Age Uncertainty"). See online version for colors.

Paris-Saclay $(680 \pm 430 \mu \mathrm{g} C ; \mathrm{n}=30)$, they show similar age-dependent age uncertainties (Figures 7 and $8 \mathrm{a}$ ), which illustrates the high precision of MICADAS graphite ${ }^{14} \mathrm{C}$ measure-ments despite overall lower sample size requirements.

The difference in uncertainties between gas and graphite ${ }^{14} \mathrm{C}$ measurements of a factor of $2.2 \pm$ 0.4 over the last $26 \mathrm{kyr}$ BP can be attributed to analytical differences. Graphitized samples are less likely to produce equal-mass molecules, have a higher ionization and transmission efficiency, which overall leads to better counting statistics. The counting statistics of gas analyses may be significantly influenced by the experimental setup, e.g., by the number of targets used for a sample analysis, the number of replicates, the duration of the analysis as well as the accuracy and precision of the (IAEA) standard measurements used for correction and normalization. Reliable ${ }^{14} \mathrm{C}$ age analysis on solid samples with MICADAS at the University of Bern can be performed on samples at least as low as $\sim 70 \mu \mathrm{g} \mathrm{C}\left(\sim 600 \mu \mathrm{g} \mathrm{CaCO}_{3}\right)$, which was the smallest graphitized sample in our experiments. ${ }^{14} \mathrm{C}$ analyses on gas samples with MICADAS provide reliable ${ }^{14} \mathrm{C}$ age estimates below these limits, despite a reduced precision.

The strong link between ${ }^{14} \mathrm{C}$ age and ${ }^{14} \mathrm{C}$ age uncertainty for normal-sized to large samples can be attributed to the fact that ${ }^{14} \mathrm{C}$ concentrations (and hence the likelihood for detection of non-sample ${ }^{14} \mathrm{C}$ or ${ }^{14} \mathrm{C}$-equivalent molecules) decrease (increases) exponentially with ${ }^{14} \mathrm{C}$ age, which has a strong impact on AMS counting statistics. If sufficiently large, all samples are equal in terms of counting statistics to some extent, because the sample $\mathrm{CO}_{2}$ concentration in He prior to injection into the AMS for gas analyses is limited to $5 \%$ and the duration of the analysis is not dependent on the sample size. However, counting statistics significantly deteriorate for very small samples, for instance when the duration of the analysis becomes significantly shortened, causing a strong dependence of ${ }^{14} \mathrm{C}$ age uncertainties on both sample age and -size.

\footnotetext{
Contributions to Overall ${ }^{14} \mathrm{C}$ Age Uncertainty

Uncertainties of reported ${ }^{14} \mathrm{C}$ ages depend to some extent on the correction protocols applied, because every procedure, e.g., cross-contamination correction, blank correction,
} 
(a)

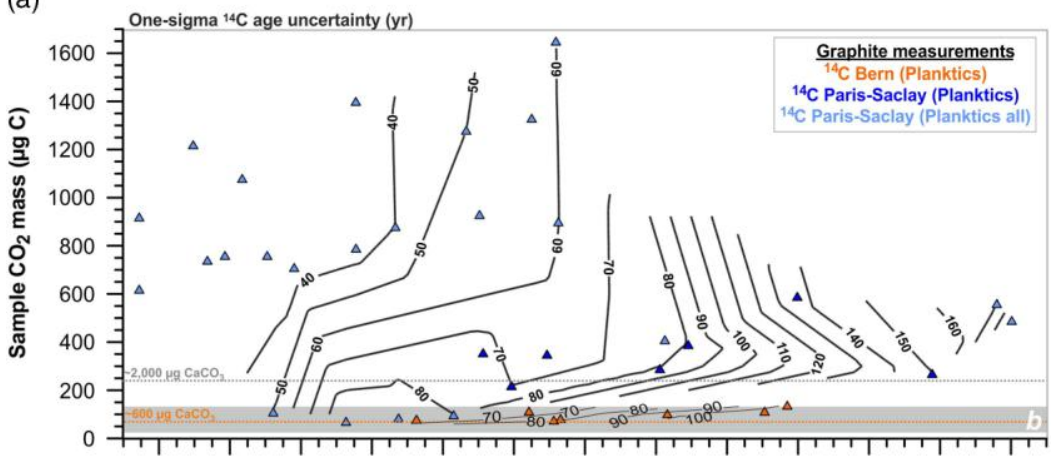

(b)

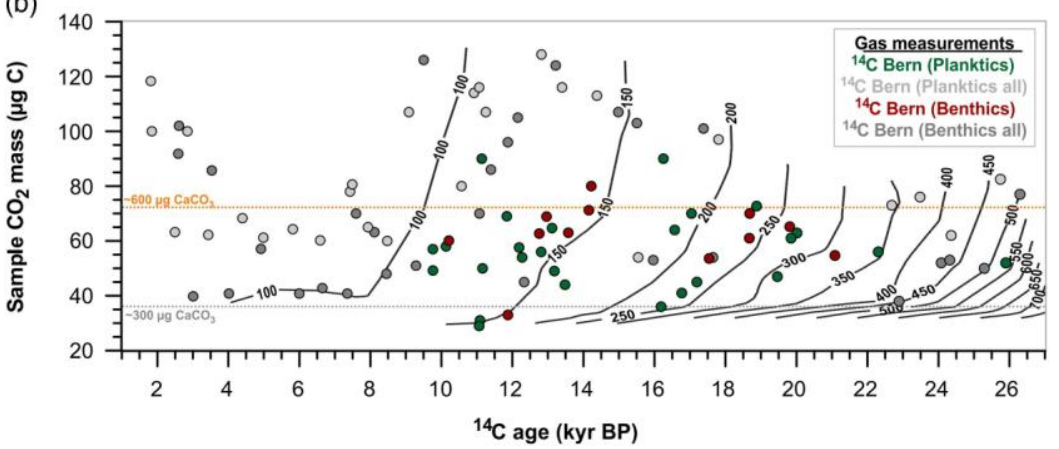

Figure 8 One-sigma ${ }^{14} \mathrm{C}$ age uncertainties of planktic and mixed benthic foraminiferal samples (foraminiferal blank not subtracted) from sediment core MD12-3396Q measured as

(a) graphite (triangle) and (b) as gas (circle) at the University of Bern (MICADAS AMS) and the University of Paris-Saclay (ARTEMIS Pelletron AMS) as function of sample ${ }^{14} \mathrm{C}$ age and sample size, shown as contours (in yr). Contours of ${ }^{14} \mathrm{C}$ age uncertainties of graphite samples were determined separately for the Bern (small samples) and Paris-Saclay dataset (large samples). Colored symbols refer to the data shown in Figures 5 and 6. Gray symbols show all data obtained in both laboratories (including those without replicate analyses). The gray box in (a) shows the range of panel (b). Gray stippled lines show boundaries below which age uncertainties of graphite (a) and gas measurements (b) are strongly dependent on both sample size and ${ }^{14} \mathrm{C}$ age. Note that ${ }^{14} \mathrm{C}$ age uncertainties are to some extent dependent on protocols of normalization and data correction that may differ among laboratories (see the section "Contributions to Overall ${ }^{14} \mathrm{C}$ Age Uncertainty"). See online version for colors.

contamination correction and standard normalization, adds to the overall uncertainty of the corrected ${ }^{14} \mathrm{C}$ age (to various degrees). Although uncertainties of ${ }^{14} \mathrm{C}$ ages should account for AMS counting statistics, the various background and blank contributions and fractionation effects as well as uncertainties associated with sample ${ }^{14} \mathrm{C}$ age reproducibility, their calculation is not standardized and can differ among laboratories. Age uncertainties determined in this study are dependent on sample size and sample age, but are not universal and strictly reflect the analysis and correction protocols applied in our laboratory.

A relatively large contribution to the overall ${ }^{14} \mathrm{C}$ age uncertainty arises from the correction of the sizedependent contamination bias owing to uncertainties inherent to the determination of the constant contamination model parameters $\mathrm{m}_{\mathrm{c}}$ and $\mathrm{F}^{14} \mathrm{C}_{\mathrm{c}}$ (for which we have applied a conservative error estimate of $\pm 15 \%$ ). This correction step can be replaced by a simple blank subtraction, if sample sizes can be precisely matched with those of the IAEA standards used for correction and 
normalization, which would reduce uncertainties of ${ }^{14} \mathrm{C}$ ages. Comparing the standard deviation of our IAEA-C1 and $\mathrm{C} 2$ standard values with the mean of their uncertainties shows that our given uncertainty estimates fully account for and possibly overestimate the variability of the IAEA-C1 and $\mathrm{C} 2$ data. This suggests that all components of uncertainty are considered conservatively by our data correction and normalization protocols.

\section{CONCLUSIONS}

Along with carbonate IAEA standards $\mathrm{C} 1$ and $\mathrm{C} 2$ as well as gaseous OxII and fossil (blank) $\mathrm{CO}_{2}$ samples, we have performed systematic ${ }^{14} \mathrm{C}$ analyses of planktic and benthic foraminifera extracted from sediment cores from the South Indian Ocean (MD12-3396Q, MD11-3355) and Ontong-Java-Plateau (RNDB-74P) with the MICADAS AMS at the University of Bern and in the ARTEMIS laboratory at the University of Paris-Saclay. The average mass of (non- ${ }^{14} \mathrm{C}$-free) samples measured as gas $\left(50 \pm 10 \mu \mathrm{g} \mathrm{C} ; 420 \pm 80 \mu \mathrm{g} \mathrm{CaCO}_{3}\right)$ and graphite $(100 \pm 20 \mu \mathrm{g} \mathrm{C} ; 830 \pm$ $\left.170 \mu \mathrm{g} \mathrm{CaCO}_{3}\right)$ at the University of Bern was smaller than samples measured with a conventional AMS (Pelletron) system at the University of Paris-Saclay $(380 \pm 130 \mu \mathrm{g} \mathrm{C} ; 3170 \pm 1080 \mu \mathrm{g}$ $\mathrm{CaCO}_{3}$ ) by a factor of 8 and 4 , respectively.

Analyses of fossil (blank) $\mathrm{CO}_{2}$ and NIST standard OxII agree with the consensus values within one-sigma uncertainties. The accuracy of ${ }^{14} \mathrm{C}$ gas analyses with MICADAS is comparable to conventional analyses. Blank values of our ${ }^{14} \mathrm{C}$-free foraminiferal samples are significantly different from zero. Although a universal foraminiferal blank correction in an ocean region or in a single sediment core does not likely exist, we suggest that foraminiferal blank corrections based on ${ }^{14} \mathrm{C}$-free foraminifera from the same core $(>100 \mathrm{kyr})$ may alleviate an overestimation of true ${ }^{14} \mathrm{C}$ ages. We find that the reproducibility of gas ${ }^{14} \mathrm{C}$ analyses of our small planktic and mixed benthic foraminiferal samples $\left({ }^{14} \mathrm{C}\right.$ age $\left.=20.2-1.8 \mathrm{kyr} \mathrm{BP}\right)$ is $200 \mathrm{yr}(\mathrm{n}=9)$ and $130 \mathrm{yr}(\mathrm{n}=4)$, respectively. The precision of our gas analyses with the MICADAS at the University of Bern decreases mainly as a function of ${ }^{{ }^{4}} \mathrm{C}$ age for sample sizes above $40 \mu \mathrm{g} \mathrm{C}\left(>300 \mu \mathrm{g} \mathrm{CaCO}_{3}\right)$. Below this limit, precision deteriorates substantially with decreasing sample size. Uncertainties of ${ }^{14} \mathrm{C}$ ages amount to $110 \mathrm{yr}$ for foraminiferal samples younger than $12 \mathrm{kyr} \mathrm{BP}$ and between 110 and $550 \mathrm{yr}$ for foraminiferal samples between 12-26 kyr BP. Uncertainties of foraminiferal ${ }^{14} \mathrm{C}$ ages analyzed on graphite with the MICADAS at the University of Bern and the Pelletron AMS at the University of Paris-Saclay are on average lower by a factor of $2.2 \pm 0.4$ than those of gas analyses. Gas ${ }^{14} \mathrm{C}$ analyses of small samples $\left(400 \pm 800 \mu \mathrm{g} \mathrm{CaCO}_{3}\right)$ and graphite ${ }^{14} \mathrm{C}$ analyses of large samples $\left(3200 \pm 1100 \mu \mathrm{g} \mathrm{CaCO}_{3}\right)$ agree within $100 \pm 60 \mathrm{yr}(\mathrm{n}=7)$, despite an average sample mass difference by a factor $\sim 8$.

Foraminiferal ${ }^{14} \mathrm{C}$ analyses on solid samples (graphite) with the MICADAS at the University of Bern provide accurate and precise ${ }^{14} \mathrm{C}$ age estimates for samples sizes at least as low as $\sim 70 \mu \mathrm{g} \mathrm{C}(\sim 600 \mu \mathrm{g}$ $\mathrm{CaCO}_{3}$ ), while foraminiferal ${ }^{14} \mathrm{C}$ analyses on gaseous samples provide a sufficiently accu-rate alternative for ${ }^{14} \mathrm{C}$ dating of samples as low as $\sim 10-30 \mu \mathrm{g} \mathrm{C}\left(\sim 30-240 \mu \mathrm{g} \mathrm{CaCO}_{3}\right)$, despite lower precision. Significant age determination of foraminiferal samples in gaseous and solid form from our study sites with the MICADAS at the University of Bern is currently limited to $38 \mathrm{kyr}$ and $42 \mathrm{kyr}$, respectively. However, ${ }^{14} \mathrm{C}$ analyses of IAEA-C1 standard material indicate that reliable ${ }^{14} \mathrm{C}$ age analyses are possible for carbonate material with a ${ }^{14} \mathrm{C}$ age up to $45 \mathrm{kyr}$ (gas) and $50 \mathrm{kyr}$ (graphite).

\section{ACKNOWLEDGMENTS}

We thank the staff of the Laboratoire de Mesure du Carbone-14 of the ARTEMIS French national AMS facility for the technical support received throughout the study. We thank Dr. Luke Skinner and Dr. Lukas Wacker for insightful discussions, and Patrick Rafter and an 
anonymous reviewer for a thorough evaluation of the manuscript that helped to improve the study. J.G. and S.L.J. acknowledge funding from the Swiss National Science Foundation (grants PP00P2_144811 and 200021_163003). J.L. was supported by the FP7-PEOPLE-2013-IEF, Marie Curie proposal 622483. This study was supported by a promotion grant from the Intermediate Staff Association of the University of Bern (to J.G.).

\section{REFERENCES}

Andrée M, Oeschger H, Broecker WS, Beavan N, Mix A, Bonani G, Hofmann HJ, Morenzoni E, Nessi M, Suter M, Wölfli W. 1986. AMS radio-carbon dates on foraminifera from deep sea sedi-ments. Radiocarbon 28(2A):424-8. doi: 10.1017/ S0033822200007542.

Bard E, Tuna T, Fagault Y, Bonvalot L, Wacker L, Fahrni S, Synal HA. 2015. AixMICADAS the accelerator mass spectrometer dedicated to ${ }^{14} \mathrm{C}$ recently installed in Aix-en-Provence France. Nuclear Instruments and Methods in Physics Research B 361:80-6. doi: 10.1016/j.nimb.2015. 01.075.

Barker S, Broecker W, Clark E, Hajdas I. 2007. Radiocarbon age offsets of foraminifera resulting from differential dissolution and fragmentation within the sedidmentary bioturbated zone. Paleoceanography 22:1-11. doi: 10.1029/2006PA001354.

Berger WH, Yasuda MK, Bickert T, Wefer G. 1996. Reconstruction of atmospheric $\mathrm{CO}_{2}$ from ice-core data and the deep-sea record of Ontong Java plateau: the Milankovitch chron. Geol. Rundschau 85:466-95. doi: 10.1007/BF02369003.

Broecker W, Barker S, Clark E, Hajdas I, Bonani G. 2006. Anomalous radiocarbon ages for foraminifera shells. Paleoceanography 21. doi: 10.1029/2005PA001212.

Brown TA, Southon JR. 1997. Corrections for contamination background in AMS ${ }^{14} \mathrm{C}$ measurements. Nuclear Instruments and Methods in Physics Research B 123:208-13. doi: 10.1016/ S0168-583X(96)00676-3.

Delqué-Kolic E, Comby-Zerbino C, Ferkane S, Moreau C, Dumoulin JP, Caffy I, Souprayen C, Quilès A, Bavay D, Hain S, Setti V. 2013. Pre-paring and measuring ultra-small radiocarbon samples with the ARTEMIS AMS facility in Saclay France. Nuclear Instruments and Methods in Physics Research B 294:189-93. doi: 10.1016/j. nimb.2012.08.048.

Ezat MM, Rasmussen TL, Thornalley DJR, Olsen J, Skinner LC, Hönisch B, Groeneveld J. 2017. Ventilation history of Nordic Seas overflows during the last (de)glacial period revealed by species-specific benthic foraminiferal ${ }^{14} \mathrm{C}$ dates. Paleoceanography. 172-81. doi: 10.1002/2016PA003053.

Fahrni SM, Wacker L, Synal HA, Szidat S. 2013. Improving a gas ion source for ${ }^{14} \mathrm{C}$ AMS. Nuclear Instruments and Methods in Physics Research B 294:320-7. doi: 10.1016/j.nimb.2012.03.037.

Freeman E, Skinner LC, Reimer R, Scrivner A, Fallon S. 2016. Graphitization of small carbonate samples for palaeoceanographic research at the Godwin Radiocarbon Laboratory University of Cambridge. Radiocarbon 58(1). doi: 10.1017/ rdc.2015.8.

Gottschalk J, Skinner LC, Lippold J, Vogel H, Frank N, Jaccard SL, Waelbroeck C. 2016. Biological and physical controls in the Southern Ocean on past millennial-scale atmospheric $\mathrm{CO}_{2}$ changes. Nat. Commun. 7 doi: 10.1038/ncomms11539.

Hua Q, Zoppi U, Williams AA, Smith AM. 2004. Small-mass AMS radiocarbon analysis at ANTARES. Nuclear Instruments and Methods in Physics Research B 223-4:284-92. doi: 10.1016/j. nimb.2004.04.057.

Jenk TM, Szidat S, Schwikowski M, Gäggeler HW, Wacker L, Synal HA, Saurer M. 2007. Micro-gram level radiocarbon $\left({ }^{14} \mathrm{C}\right)$ determination on carbonaceous particles in ice. Nuclear Instruments and Methods in Physics Research B 259:518-25. doi: 10.1016/j.nimb.2007.01.196.

Lindsay CM, Lehman SJ, Marchitto TM, Ortiz JD. 2015. The surface expression of radiocarbon anomalies near Baja California during deglaciation. Earth Planetary Science Letters 422:67-74. doi: 10.1016/j.epsl.2015.04.012.

Magana AL, Southon JR, Kennett JP, Roark EB, Sarnthein M, Stott LD. 2010. Resolving the cause of large differences between deglacial benthic foraminifera radiocarbon measurements in Santa Barbara Basin. Paleoceanography 25:1-8. doi: 10.1029/2010PA002011.

Mazaud A, Kissel C, Laj C, Sicre MA, Michel E, Turon JL. 2007. Variations of the ACC-CDW during MIS3 traced by magnetic grain deposition in midlatitude South Indian Ocean cores: con-nections with the Northern Hemisphere and with central Antarctica. Geochemistry Geophys. Geo-systems. 8 doi: 10.1029/2006GC001532.

Moreau C, Caffy I, Comby C, Delqué-Kolic E, Dumoulin JP, Hain S, Quilès A, Setti V, Souprayen C, Thellier B, Vincent J. 2013. Research and development of the ARTEMIS ${ }^{14} \mathrm{C}$ AMS facility: status report. Radiocarbon 55(2):331-7. doi: 10.2458/azu_js_rc.55.16293.

Nadeau M-J, Grootes PM, Voelker A, Bruhn F, Duhr A, Oriwall A. 2001. Carbonate ${ }^{14} \mathrm{C}$ background: does it have multiple personalities? Radiocarbon 43(2A): 169-76. doi: 10.1017/S0033822200037978.

Pearson A, McNichol AP, Schneider RJ, von Reden KF, Zheng Y. 1998. Microscale ${ }^{14}$ C AMS measurement at NOSAMS. Radicarbon 40(1):61-75. doi: 10.1017/S0033822200017902. 
Reimer PJ, Brown TA, Reimer RW. 2004. Discussion: reporting and calibration of post-bomb ${ }^{14} \mathrm{C}$ data. Radiocarbon 46(3):1299-304. doi: 10.1017/ S0033822200033154.

Roach LD, Charles CD, Field DB, Guilderson TP. 2013. Foraminiferal radiocarbon record of northeast Pacific decadal subsurface variability. J. Geophys. Res. Ocean 118:4317-33. doi: 10.1002/jgrc.20274.

Rozanski K. 1991. Consultants' group meeting on ${ }^{14} \mathrm{C}$ reference materials for radiocarbon laboratories. Internal Report, IAEA, Vienna, Austria.

Rozanski K, Stichler W, Gonfiantini R, Scott EM, Beukens RP, Kromer B, van der Plicht J. 1992. The IAEA ${ }^{14} \mathrm{C}$ intercomparison exercise 1990. Radiocarbon 34(3):506-19. doi: 10.1017/S00338 22200063761.

Ruff M, Szidat S, Gäggeler HW, Suter M, Synal H, Wacker L. 2010a. Gaseous radiocarbon measurements of small samples. Nuclear Instruments and Methods in Physics Research B 268:790-4. doi: 10.1016/j.nimb.2009.10.032.

Ruff M, Fahrni S, Gäggeler H, Hajdas I, Suter M, Synal H-A, Szidat S, Wacker L. 2010b. On-line radiocarbon measurements of small samples using elemental analyzer and MICADAS gas ion source. Radiocarbon 52(4):1645-56. doi: 10.1017/S003382220005637X.

Ruff M, Wacker L, Gäggeler HW, Suter M, Synal H-A, Szidat S. 2007. A gas ion source for radiocarbon measurements at $200 \mathrm{kV}$. Radiocarbon 49(2):30714. doi: $10.1017 / \mathrm{S} 0033822200042235$.

Salazar G, Zhang YL, Agrios K, Szidat S. 2015. Development of a method for fast and automatic radiocarbon measurement of aerosol samples by online coupling of an elemental analyzer with a MICADAS AMS. Nuclear Instruments and Methods in Physics Research B 361:163-7. doi: 10.1016/j.nimb.2015.03.051.

Santos GM, Southon JR, Griffin S, Beaupre SR, Druffel ERM. 2007a. Ultra small-mass AMS ${ }^{14} \mathrm{C}$ sample preparation and analyses at KCCAMS/ UCI facility. Nuclear Instruments and Methods in Physics Research B 259:293-302. doi: 10.1016/j. nimb.2007.01.172.

Santos GM, Southon JR, Drenzek NJ, Ziolkowski LA, Druffel E, Xu X, Zhang D, Trumbore S, Eglinton TI, Hughen KA. 2007b. Blank assessment for ultrasmall radiocarbon samples: chemical extraction and separation versus AMS. Radiocarbon 52:1322-35. doi: 10.2458/azu_js_rc.52.3631.

Schleicher M, Grootes PM, Nadeau M-J, Schoon A. 1998. The carbonate ${ }^{14} \mathrm{C}$ background and its components at the Leibniz AMS facility. Radiocarbon 40(1):85-93. doi: 10.1017/S0033822200017926.

Schulze-König T, Seiler M, Suter M, Wacker L, Synal HA. 2011. The dissociation of ${ }^{13} \mathrm{CH}$ and ${ }^{12} \mathrm{CH}_{2}$ molecules in $\mathrm{He}$ and $\mathrm{N}_{2}$ at beam energies of 80-250 $\mathrm{keV}$ and possible implications for radio-carbon mass spectrometry. Nuclear Instruments and Methods in Physics Research B 269:34-9. doi: 10.1016/j.nimb.2010.09.015.
Shah Walter SR, Gagnon AR, Roberts ML, McNichol AP, Lardie Gaylord MC, Klein E. 2015. Ultrasmall graphitization reactors for ultra-microscale ${ }^{14} \mathrm{C}$ analysis of the National Ocean Sciences Accelerator Mass Spectrometry (NOSAMS) facility. Radiocarbon 57(1):109-22. doi: 10.2458/azu_rc.57.18118.

Smith AM, Yang B, Hua Q, Mann M. 2010. Laserheated microfurnace: gas analysis and graphite morphology. Radiocarbon 52(2):769-82. doi: 10.1017/S0033822200045781.

Stuiver M, Polach HA. 1977. Discussion: reporting of ${ }^{14}$ C data. Radiocarbon 19(3):355-63. doi: 10.1017/ S0033822200003672.

Suter M, Jacob S, Synal H-A. 1997. AMS of ${ }^{14} \mathrm{C}$ at low energies. Nuclear Instruments and Methods in Physics Research 123:148-52. doi: 10.1016/S0168-583X(96)00613-1.

Synal HA. 2013. Developments in accelerator mass spectrometry. Int. J. Mass Spectrom 349-50: 192202. doi: 10.1016/j.ijms.2013.05.008.

Synal HA, Jacob S, Suter M. 2000. New concepts for radiocarbon detection systems. Nuclear Instruments and Methods in Physics Research B 161: 29-36. doi: 10.1016/S0168-583X(99)00881-2.

Synal H, Stocker M, Suter M. 2007. MICADAS: a new compact radiocarbon AMS system. Nuclear Instruments and Methods in Physics Research B 259:7-13. doi: 10.1016/j.nimb.2007.01.138.

Szidat S, Salazar GA, Vogel E, Battaglia M, Wacker L, Synal HA, Türler A. 2014. ${ }^{14} \mathrm{C}$ analysis and sample preparation at the new Bern Laboratory for the Analysis of Radiocarbon with AMS (LARA). Radiocarbon 56(2):561-6. doi: 10.2458/56.17457.

Szidat S, Vogel E, Gubler R, Lösch S. 2017. Radiocarbon dating of bones at the LARA laboratory in Bern Switzerland. Radiocarbon 59(3):831-42. doi: 10.1017/RDC.2016.90.

Vogel JS, Nelson DE, Southon JR. 1987. ${ }^{14}$ C background levels in an accelerator mass spectrometry system. Radiocarbon 29(3):323-33. doi: $10.1017 /$ S0033822200043733.

Vogel JS, Southon JR, Nelson DE, Brown TA. 1984. Performance of catalytically condensed carbon for use in accelerator mass spectrometry. Nuclear Instruments and Methods in Physics Research 5:289-93. doi: 10.1016/0168-583X(84)90529-9.

Wacker L, Bonani G, Friedrich M, Hajdas I, Kromer B, Nemec M, Ruff M, Suter M, Synal H, Vockenhuber C. 2010a. MICADAS: routine and highprecision radiocarbon dating. Radiocarbon 52(2): 252-62. doi: 10.2458/azu_js_rc.52.3660.

Wacker L, Christl M, Synal HA. 2010b. Bats: A new tool for AMS data reduction. Nuclear Instruments and Methods in Physics Research B 268:976-9. doi: 10.1016/j.nimb.2009.10.078.

Wacker L, Fahrni SM, Hajdas I, Molnar M, Synal HA, Szidat S, Zhang YL. 2013a. A versatile gas interface for routine radiocarbon analysis with a gas ion source. Nuclear Instruments and Methods 
in Physics Research B 294:315-19. doi: 10.1016/j. nimb.2012.02.009.

Wacker L, Fülöp RH, Hajdas I, Molnár M, Rethemeyer J. 2013b. A novel approach to process carbonate samples for radiocarbon measurements with helium carrier gas. Nuclear Instruments and Methods in Physics Research B 294:214-7. doi: 10.1016/j.nimb.2012.08.030.

Wacker L, Lippold J, Molnár M, Schulz H. 2013c. Towards radiocarbon dating of single foraminifera with a gas ion source. Nuclear
Instruments and Methods in Physics Research B 294:307-10. doi: 10.1016/j.nimb.2012.08.038.

Wacker L, Nemec M, Bourquin J. 2010c. A revolutionary graphitisation system: fully automated compact and simple. Nuclear Instruments and Methods in Physics Research B 268:931-4. doi: 10.1016/j.nimb.2009.10.067.

Wycech J, Kelly DC, Marcott S. 2016. Effects of seafloor diagenesis on planktic foraminiferal radiocarbon ages. Geology 44:1-4. doi: $10.1130 /$ G37864.1. 